IZA DP No. 6750

Toward the Integration of Personality Theory and Decision Theory in the Explanation of Economic and Health Behavior

Aldo Rustichini

Colin G. DeYoung

Jon Anderson

Stephen V. Burks

July 2012 


\title{
Toward the Integration of Personality Theory and Decision Theory in the Explanation of Economic and Health Behavior
}

\author{
Aldo Rustichini \\ University of Minnesota \\ and University of Cambridge \\ Colin G. DeYoung \\ University of Minnesota \\ Jon Anderson \\ University of Minnesota, Morris \\ Stephen V. Burks \\ University of Minnesota, Morris, \\ IZA and CeDEx, University of Nottingham
Discussion Paper No. 6750
July 2012 \\ IZA
P.O. Box 7240
53072 Bonn
Germany \\ Phone: +49-228-3894-0 \\ Fax: +49-228-3894-180 \\ E-mail: iza@iza.org
}

\begin{abstract}
Any opinions expressed here are those of the author(s) and not those of IZA. Research published in this series may include views on policy, but the institute itself takes no institutional policy positions.

The Institute for the Study of Labor (IZA) in Bonn is a local and virtual international research center and a place of communication between science, politics and business. IZA is an independent nonprofit organization supported by Deutsche Post Foundation. The center is associated with the University of Bonn and offers a stimulating research environment through its international network, workshops and conferences, data service, project support, research visits and doctoral program. IZA engages in (i) original and internationally competitive research in all fields of labor economics, (ii) development of policy concepts, and (iii) dissemination of research results and concepts to the interested public.
\end{abstract}

IZA Discussion Papers often represent preliminary work and are circulated to encourage discussion. Citation of such a paper should account for its provisional character. A revised version may be available directly from the author. 


\title{
ABSTRACT
}

\section{Toward the Integration of Personality Theory and Decision Theory in the Explanation of Economic and Health Behavior}

\begin{abstract}
Trait-based personality psychology and economics have taken different approaches to understanding individual differences, with the former emphasizing variables derived from the factor analysis of trait assessments, and the latter emphasizing variables derived from formal decision theory. In a data set on trainee truckers in a large US company, we provide a systematic initial assessment of the empirical pattern of relationships between the elements from these two approaches by comparing the predictive power of measurements derived from personality theory and decision theory for several individual characteristics and outcomes, and relating the two sets of measurements to each other. We show that personality traits have a comparable or stronger predictive power than do economic preferences for several dependent variables, including credit score, job persistence, and heavy truck accidents. They also have strong predictive power for Body Mass Index (BMI) and smoking status. Further, decision theory and personality variables are meaningfully related. For example, we confirm that cognitive ability explains a substantial part of time preferences, and find that Neuroticism and cognitive ability together explain attitudes toward risk. In addition, Agreeableness and cognitive ability explain aspects of other-regarding behavior in a strategic setting.
\end{abstract}

JEL Classification: D83, C72, C93

Keywords: personality theory, decision theory, strategic behavior, credit score, smoking, obesity, prisoners' dilemma, job performance, heavy truck accident, truckload, turnover, trucker

Corresponding author:

Stephen V. Burks

University of Minnesota, Morris

Division of Social Sciences

600 East 4th Street

Morris, MN 56267-2134

USA

E-mail: svburks@morris.umn.edu

\footnotetext{
* The authors benefitted from comments received at the Institute for the Study of Labor (IZA) Workshop on Cognitive and Non-Cognitive Skills (January, 2011) and at the American Economic Association session on Personality Theory, Decision Theory and Economics at the Allied Social Science Association meetings (January, 2012). The authors gratefully acknowledge generous financial support for the Truckers and Turnover Project from the John D. and Catherine T. MacArthur Foundation's Research Network on the Nature and Origin of Preferences, the Alfred P. Sloan Foundation, the Trucking Industry Program at the Georgia Institute of Technology, and the University of Minnesota, Morris, and both financial and in-kind support from the cooperating motor carrier, its staff, and its executives. Rustichini also thanks the NSF (grant SES-0924896). The views expressed are those of the authors, and do not necessarily reflect the views of any of the supporting institutions.
} 


\section{Personality Theory and Decision Theory}

Two prominent approaches to understanding human behavior are decision theory, emanating originally from Economics, and personality theory, emanating from Psychology. The research we present here is a first step in the attempt, as initially proposed in Rustichini (2009), to integrate the different views of human behavior generated by these two approaches. ${ }^{1}$ Both approaches were designed to provide a comprehensive description of important influences on behavior. However, the variables used to predict behavior in classical decision theory are derived from the a priori analysis of rational behavior, whereas personality theory typically derives its variables empirically, from patterns of correlation in measurements of the frequency and intensity of a wide variety of behaviors.

Decision theory in its classical form focuses on choices individuals make among options, which typically are payments to be received subject to uncertainty and at different points in the future. For example, an individual may have to choose among an earlier and smaller payment and a later, larger payment. Or he may have to choose between a sure amount (say the payment of 45 dollars for sure) or a random payment, called a lottery, (say the payment of 100 dollars with 50 per cent probability, and zero with the complementary probability). Combinations of these two basic components are possible: an individual may have to choose between two lotteries at two different points in time. The preferences of an individual over options like the ones we described are summarized by a utility function, which assigns a single number to each option; the individual chooses the option with the largest number. Decision Theory identifies the essential elements determining behavior as two attitudes, one towards decision making under uncertainty and the other towards the allocation over time of rewards and penalties. When very specific functional forms are assumed for an individual's utility, that individual is completely described by a risk aversion level and a discount factor. Extensions of the simple theory, like Prospect Theory (Kahneman and Tversky 1979) or the theory of ambiguity aversion (Ellsberg 1961, Schmeidler 1989), increase the number

\footnotetext{
${ }^{1}$ Borghans et al. (2008) similarly called for research attempting to integrate personality and decision theory. Our approach is distinguished from theirs in part by the theoretical position that cognitive skills should be considered as an integrated component of an individual's personality, rather than as categorically distinct from personality (DeYoung 2011).
} 
of parameters and the complexity of the representation of preferences, but the basic structure is unchanged.

In personality psychology there is a reasonably widespread consensus that only five or six dimensions underlie the major patterns of covariation in human behavior. The Five Factor Model is the most widely used and well-validated taxonomy of personality traits, using five dimensions (the "Big Five”) to describe personality: Extraversion, Neuroticism, Agreeableness, Conscientiousness, and Openness/Intellect (John, Naumann and Soto 2008). Scores of an individual on the Big Five characterize his or her stable pattern of actions, thoughts, and feelings, and can be used to predict the individual's behavior. However, personality theory also specifies that personality traits are organized hierarchically, such that each of the Big Five traits subsumes multiple lower level traits (typically called facets), with unique variance not entirely explained by the Big Five. Thus, although five dimensions are thought to provide a reasonably comprehensive description of an individual's characteristics, they are not intended to be exhaustive.

Because personality and decision theory appear to identify distinct sets of enduring human characteristics, one approach to integrating them is simply to take their union. This provides an ad hoc model of human nature, in which seven parameters describe an individual and predict his or her behavior. If we want to distinguish, within the decisiontheoretic traits, between the attitudes toward risk in gains versus in losses (as we will here) we have eight parameters; if we add facets, more narrow traits within the broad domains from personality theory, the number is even larger. We apply this ad hoc model to an extensive set of data from a large-scale behavioral economic field study with 1,065 trainee truck drivers, combined with information about the behavior of subjects on the job for up to two years (Burks, Carpenter and Götte 2009, Burks, Carpenter, Götte, Monaco, Porter and Rustichini 2008, Burks, Carpenter, Götte and Rustichini 2009). Our strategy for integrating personality and decision theory is to begin by relating the components of each theory to each other and comparing their predictive power. This information then guides the beginnings of a synthesis.

The advantage of the data used here is that they contain measures of all the characteristics in the ad hoc model, so we can examine how these traits relate to each other, while controlling for the sorts of demographic characteristics economists normally 
use in human capital models. In addition, we have data on three contemporaneously measured life outcomes, smoking status, body mass index, and credit score, as well as data on two key longitudinal outcomes: (1) the length of job attachment and reason for departure, in a high-turnover setting with a financial penalty for early exit, and (2) the number of truck accidents, controlling for week-by-week variations in the exposure to accident risk. These data allow examination of how the different traits in the ad hoc model predict, or fail to predict, several distinct outcomes.

\subsection{The Big Five in a Theoretical Context}

The Big Five model itself is not typically considered a theory, as it was created to provide only a description of personality rather than an explanation of the sources of its dimensions. In order to develop a theory of the Big Five, what is needed is to identify the psychological mechanisms that generate the regularities in behavior described by each dimension (DeYoung 2010, DeYoung 2010). A number of researchers have proposed mechanisms associated with the Big Five, with a reasonable degree of agreement (Denissen and Penke 2008, DeYoung 2010, DeYoung, Hirsh, Shane, Papademetris, Rajeevan and Gray 2010, Nettle 2006, Van Egeren 2009). In this theoretical scheme, Extraversion reflects sensitivity to reward, both incentive (i.e., cues that indicate the possibility of reward) and consummatory (i.e., reaction to receiving reward). Extraversion is often expressed in a social context because many of the most important human rewards are social (e.g., social status or social affiliation), but Extraversion also encompasses the general tendency toward positive affect. Neuroticism reflects reactivity to threat and punishment and manifests in the experience of negative affect and associated cognition such as self-consciousness and rumination. Agreeableness reflects the tendency toward altruism and cooperation, as opposed to exploitation and disregard of others. Conscientiousness reflects the ability and tendency to exert control over behavior and impulses in order to follow rules and pursue nonimmediate goals. Openness/Intellect reflects the ability and tendency to seek, detect, comprehend, and utilize patterns of information, both sensory and abstract.

Because the Big Five are designed to be reasonably comprehensive, this theoretical approach may offer an adequate list of the major types of psychological function in which there is substantial variation between individuals. Further, the mechanisms that 
are hypothesized to generate behaviors for each of the Big Five must be specifiable as components of a single mind and brain, which means that they must interact within the individual to produce behavior (Block 2002, DeYoung 2010, Van Egeren 2009). These premises provide an important motivation for integrating decision theory and personality theory. The variables described by decision theory should be explicable in terms of and in relation to the set of mechanisms associated with the Big Five. If they cannot be, this poses a problem for personality theory.

\subsection{The Big Five Hierarchy}

Before proceeding to our hypotheses, we further explicate the hierarchical structure of personality associated with the Big Five, which guided our selection of personality measures from those available within our sample. The sample completed the Multidimensional Personality Questionnaire (MPQ) (Tellegen and Waller 2008, Tellegen 1982) rather than an instrument designed to measure the Big Five. However, the 11 subscales of the MPQ can be mapped onto the Big Five (Markon, Krueger and Watson 2005). The personality hierarchy organizes a large number of facet-level traits within the Big Five. There is no consensus as to the number and identity of facets in each domain. However, a level of personality structure has been empirically identified between the Big Five and their facets, which indicates that each of the Big Five can be divided into two separate but correlated aspects (DeYoung, Quilty and Peterson 2007, Jang, Livesley, Angleitner, Riemann and Vernon 2002). These aspect-level traits provide basic, important distinctions between different lower-level traits in the Big Five, and can predict outcomes divergently. For example, the two aspects of Agreeableness, Compassion and Politeness, predict political attitudes in opposite directions (Hirsh, DeYoung and Peterson 2009). Extraversion is divided into an Assertiveness aspect, reflecting drive, leadership, and dominance, and an Enthusiasm aspect reflecting sociability and positive emotions. The MPQ scales Social Potency and Social Closeness correspond to the two aspects of Extraversion and have opposite effects on selfconfidence and over-confidence (Burks, Carpenter, Götte and Rustichini 2010). For our study, the two aspects of Conscientiousness are particularly important. Conscientiousness has long been conceptualized as having an inhibitive side and a 
proactive side (Costa, McCrae and Dye 1991), and these appear to correspond to the aspects Orderliness and Industriousness identified by DeYoung et al. (2007).

Also important for our study is the division of Openness/Intellect into distinct aspects of Intellect and Openness. This division allows for a more thorough integration of the concept of intelligence within standard personality models than has previously been available (DeYoung 2011, DeYoung, Grazioplene and Peterson forthcoming 2012). Descriptors of intelligence fall within Openness/Intellect in factor analyses that reveal the Big Five (Goldberg 1990, Saucier 1992). Additionally, of the Big Five, only Openness/Intellect is positively associated with ability tests of intelligence (Ackerman and Heggestad 1997, DeYoung 2011), and intelligence test scores sometimes fall within Openness/Intellect in factor analysis (DeYoung, Grazioplene and Peterson forthcoming 2012). However, when the Big Five dimension was construed simply as Openness to Experience, intelligence did not appear to have much conceptual overlap (McCrae and Costa 1997). Recognizing Intellect as a distinct aspect of the domain makes the overlap more apparent.

Items from the Intellect factor describe both intellectual engagement (e.g., “Avoid philosophical discussions”-reversed) and perceived intelligence (e.g., “Am quick to understand things”).When both Intellect and Openness are used as simultaneous predictors, only Intellect is associated with intelligence tests, and when Openness and Intellect are separated in factor analysis, intelligence loads only on Intellect (DeYoung, Grazioplene and Peterson forthcoming 2012, DeYoung, Quilty, Peterson and Gray forthcoming 2012, DeYoung, Shamosh, Green, Braver and Gray 2009). Because of the established importance of intelligence for predicting economic outcomes and variables, and because the MPQ does not contain a scale corresponding to Intellect, we utilized cognitive ability tests to assess this class of personality traits. Some have argued that personality encompasses only typical behavior, not ability, but this has never been an assumption of the Big Five model. Abilities influence typical behavior, and traits involving abilities can also be found in Big Five domains other than Openness/Intellect (e.g., ability to resist distraction in Conscientiousness, or ability to empathize in Agreeableness).

\subsection{Hypotheses: personality traits and economic preferences}


The link between personality characteristics and economic preferences has been analyzed in recent literature in psychology and economics, and some preliminary conjectures can be proposed. Time preferences are reliably related to intelligence. Higher intelligence is associated, everything else being equal, with a higher willingness to postpone the acquisition of a reward. Meta-analysis of 26 effect sizes found a negative correlation of $r=-.23$ between intelligence and patience in delay discounting tasks (Shamosh and Gray 2008). The same negative correlation has been found by Burks et al. (2009), using the data we consider here, in choices of subjects who had to choose between an earlier (not necessarily immediate) payment and a later and larger one. The effect of intelligence was similar on both choices in which the earlier payment was immediate and those in which it was not. Looking for the mechanisms supporting this association, Shamosh et al. (2008) assessed intelligence, performance in a working memory (WM) task, and hypothetical choices in a delay discounting (DD) task in a large sample of healthy adults $(N=103)$. Subjects chose between immediate and delayed payments in all choices. The behavioral findings confirmed the negative association between patience (choice of the later payment) in the DD task and both intelligence and WM performance. Additionally, subjects' brains were scanned with fMRI as they were performing the WM task, and task-related neural activity in the left anterior prefrontal cortex was associated positively with intelligence $(r=.26)$ and negatively with delay discounting $(r=-.40)$. These and other results suggest that preferences over time delays in monetary payments are correlated with intelligence because of the recruitment of brain regions that perform abstract information processing and integration.

One might hypothesize that both Conscientiousness and Extraversion should also be associated with DD. Conscientiousness describes behaviors related to self-control and avoidance of distraction in favor of longer term goals. However, at least one study reports no association of Conscientiousness with DD (Hirsh, Morisano and Peterson 2008). In contrast, several studies find positive correlations between DD and questionnaire measures of impulsivity, which is often considered to mark the low pole of Conscientiousness (Hinson, Jameson and Whitney 2003, Ostaszewski 1996, Richards, Zhang, Mitchell and de Wit 1999, Swann, Bjork, Moeller and Dougherty 2002). To the extent that Extraversion reflects sensitivity to rewards, higher Extraversion might 
increase the tendency to pursue immediate rewards when available, and at least two studies report correlations between Extraversion and DD (Hirsh, Morisano and Peterson 2008, Ostaszewski 1996).

Attitudes to risk appear to be primarily affected by Neuroticism: a higher Neuroticism score is associated with a higher aversion to risk and uncertain outcomes. Some evidence supporting this link is provided by studies linking Neuroticism to the response to experienced uncertainty. For example, Hirsch and Izlicht (2008) study the feedback-related negativity (FRN), an evoked potential peaking $250 \mathrm{~ms}$ after the receipt of feedback information for positive, negative and uncertain feedback (in the latter case, the subject was not told whether he had succeeded in the assigned task or not). A larger FRN is found to be associated with the receipt of negative than positive feedback, but more important for our present purposes, the uncertain feedback produced an even larger response than a negative one in individuals with a larger Neuroticism score.

This channel might not be exclusive. First, other personality traits may affect the aversion to risk; higher cognitive skills are associated with higher willingness to take calculated risks (i.e. those that represent fair or better-than-fair gambles for small stakes): evidence in this direction is in Burks et al. (2009). ${ }^{2}$ Second, aversion to risk is a complex trait, and individuals may differ along more than one dimension; for instance, the degree of risk aversion may vary with the stakes (that is, choices may not be invariant under scaling of the outcomes), and personality traits may affect this response.

Also the degree of risk aversion may vary depending on reference points. When this point is the zero outcome risk aversion may be smaller in the loss domain (as systematized in Prospect Theory (Kahneman and Tversky 1979)). Intelligence may modulate in part the difference in behavior in the two domains. For example, Rabin and Weizsacker (2009) show theoretically and experimentally that an individual who treats decisions separately (for example in gain and loss domain) will make sub-optimal (dominated) choices. Finally the degree of aversion to risk may be modulated by the difference in the perceived precision of the probability assigned to outcomes, or by the

\footnotetext{
${ }^{2}$ We use the term "fair gamble" in the standard way: when one chooses between a lottery and a fixed payment, a fair gamble is a lottery with an expected value equal to the fixed payment; in a better-than-fair gamble the expected value is greater than the fixed payment.
} 
degree of familiarity of the individual with the events describing outcomes. This latter set of factors has been modeled in economic theory under the concept of ambiguity aversion (Ellsberg 1961), a feature of individual preferences that might also be affected in different ways by several distinct personality traits.

\subsection{Hypotheses: personality traits and economic behavior}

There is growing evidence available of the link between personality traits and economic performances. The reviews of Ozer and Benet-Martinez, (2006), and Roberts et al. (2007) have recently added to our understanding of the predictive power for important life outcomes provided by personality measures; Ones and Viswesvaran (1998) focus on the link with performance. Roberts et al. (2007) review the predictions of three critical outcomes: mortality, divorce, and occupational attainment, on the basis of information about individual personality traits and conclude that the predictive power is comparable to that of cognitive skills and socio-economic status. For example, Conscientiousness, Extraversion and Neuroticism have weak but significant correlation with mortality. With respect to divorce, Agreeableness, Conscientiousness and Neuroticism have a correlation of between 10 and 20 per cent. With regard to occupational outcomes, the standardized beta weights of personality traits were on average more than 20 per cent; for comparison, the weight for IQ was slightly higher than 25 per cent.

\section{Experimental Design}

In this study we examine the statistical relationship between personality traits and economic preferences, and compare the effects of personality traits and economic outcomes on three contemporaneously-measured life outcomes (smoking status, body mass index, and credit score), as well as on two important longitudinally-measured outcomes: the length of job tenure and reason for departure in a high-turnover setting with a financial penalty for early exit, and the number of truck accidents, controlling for week-by-week variations in the exposure to accident risk. Our data set also contains socio-economic and demographic variables that allow us to control for the effects of the factors economists use when constructing human capital models.

\subsection{Method}


Initial data (including all the contemporaneous measures) were gathered upon intake into the study between December 2005 and August 2006 from 1,065 truck driver trainees at a Midwestern training facility of a large motor carrier. Longitudinal measures (data on accidents and the operational factors affecting the exposure to the risk of accident, and on separations from employment) were collected from the firm for each subject for the following two years, or until first exit, whichever came first. Ninety-one percent of the firm's trainees offered the chance to participate in the study did so. During the initial data collection there were between 18 and 30 participants in each participant group. The data collection was in the form of two sessions of two-hours each, with a short break in between. The first session involved five distinct activities, and the second six; eight were economic experiments, and three were questionnaires. In addition to a show-up fee of $\$ 10$ at the beginning of each of the two sessions, in all of the experimental components participants had appropriate monetary incentives. Subjects earned between \$21 and \$168 in total over the two sessions, with an average of $\$ 53$. Some details of the design and the context can be found in Section 10, an Appendix on this topic, and full account of the entire project is available in Burks et al. (2008).

\subsection{Socio-economic characteristics}

The socio-economic characteristics on which we have information are gender, age, ethnicity and education. The gender of the subject is described by the variable Female. The second is ethnic background, described by the dummy variables African-American, Native American, Asian, Latino, and by Multi-Ethnic (those reporting membership in any other group or in more than one). The omitted category is White. Marital Status is described by four categories: Separated, Divorced, and Single and Never Married; the omitted category is Married. The variable Age is in years, $\mathrm{Age}^{2}$ is its square. Information on education is represented by the following dummy variables: Less than High School, Some College, and BA or more; the omitted category is High School.

\subsection{Economic Preferences}

The measures of attitude toward risk are derived from choices made by subjects in a laboratory experiment. They were asked to choose between a simple 50-50 lottery and a certain amount, six times. In each choice the lottery was the same, and the certain amount was varied; for example, subjects were asked to choose between a 50-50 lottery 
with prizes of $\$ 1$ and $\$ 5$, and a fixed amount of $\$ 2$; then between the same lottery versus a fixed amount of $\$ 2.50$, and so on. This task was repeated four times; in two of these times the outcomes of the lotteries were all positive, and we refer to these as Gain lotteries and choices. The other two times the task was repeated, one of the outcomes of the lottery was negative (so subject could incur a small loss, of $\$ 1$ or $\$ 5$, respectively); these are the Loss lotteries. In the Gain lotteries and the Loss lottery with one outcome of $-\$ 1$, out of the six choices a risk neutral individual would choose the mixture \{lotteries, fixed payment $\}$ either of $\{4,2\}$ or of $\{5,1\}$. In the Loss lottery with one outcome of $-\$ 5$, a risk neutral individual would choose the mixture \{lotteries, fixed payments either of $\{2,4\}$ or of $\{1,5\}$. The attitude to ambiguity was measured with the same set of lotteries, but with the probabilities of the lottery outcomes not fully specified. All subjects were paid for one of their randomly selected choices in the risk and in the ambiguity activities.

The measure of acceptance of delay in payments is also derived from choices. Subjects were asked to choose seven times between an earlier smaller payment and a later larger payment. The times in the tasks were today vs. tomorrow, today vs. six days from today, two days from today vs. six days from today, and two days from today vs. four weeks and two days from today. These times of payment were chosen because subjects would still be at the training school for all but the longest-delayed payment (four weeks plus two days, which the University promised to pay by mailing a certified check to an address collected on the spot from those receiving payment). Two subjects in each group were selected at random and paid for one of their randomly selected choices on this activity.

The Risk Acceptance in Gains is the number of times the subject chose the lottery over the certain amount in the gain choices; the Acceptance in Losses is the corresponding value in the Loss choices. We consider the attitude to risk in these two separate cases because attitudes vary significantly across them. The Delay Acceptance is the number of times the subject chooses a delayed payment over an immediate payment in the time payment task.

\subsection{Personality Traits}


As mentioned in Section 1.2 the sample did not complete a standard Big Five measure; we instead used a short form of the Multidimensional Personality Inventory (MPQ), which consists of 11 trait scales (Tellegen and Waller 2008, Tellegen 1982). However, the MPQ scales can be mapped onto the Big Five; indeed, a factor analysis of the MPQ along with four other personality inventories (only one being a purpose-built Big Five instrument) revealed that the Big Five structure underlies all of these inventories (Markon, Krueger and Watson 2005). Thus, we derive our Big Five personality trait measures from the MPQ.

Almost all of the 154 questions in the short form of the MPQ have the same four possible answers: Always True, Mostly True, Mostly False, and Always False, and the subject had to choose one. In addition we asked a series of other attitudinal questions in a separate survey. There were no separate payments for the MPQ or the surveys. The Conscientiousness index is an average obtained by combining scores in the Control MPQ scale and several other related survey questions. The two sides of Conscientiousness in particular (Inhibitive and Proactive) were obtained as follows. The first is the sum of the scores of five MPQ Control scale items. The second is the sum of seven items, two from the MPQ Achievement scale, one from the MPQ Validity scale ${ }^{3}$ and four from a Risk and Impatience scale. ${ }^{4}$ The Neuroticism scale is the score on the questions on the Stress Reaction MPQ-trait. The Agreeableness scale is the reverse of the Aggression MPQ scale. The Extraversion scale is the sum of the Social Potency and the Social Closeness MPQ scales.

Following the discussion in section 1.2, we did not use a questionnaire measure of Openness/Intellect, but instead used an index of cognitive skills. Cognitive skills (CS) were measured in three different tasks. The first was a subset of Raven's Standard Progressive Matrices (SPM), a measure of non-verbal IQ (Raven, Raven and Court 2000). Subjects had to choose, out of a set of small patterned shapes, the one that matches a gap in a larger patterned shape. The second task was part of a standard test for adults of quantitative literacy, or "numeracy,” from the Educational Testing Service.

\footnotetext{
${ }^{3}$ The specific question was "Sometimes I am a bit lazy"

${ }^{4}$ For example the first of these questions was "How often do you have trouble wrapping up the final details of a project, once the challenging parts have been done?” See section 2.3 in Burks, et al. (2012 in press)
} 
Subjects had to interpret text and diagrams containing numerical information, and to do arithmetic calculations to answer the questions. For these two measures two subjects in each group selected at random were paid for correct answers. The third measure was a simple game, called Hit 15, played against the computer. Subject and computer alternated in moving. The subjects' goal in the game was to reach a total of 15 from a varying initial number less than 15, to which the player or the computer had to add between 1 and 3 points on each round. In this task, all subjects were paid for each round they won. ${ }^{5}$

We construct the Cognitive Skill Index (CSI) as the first factor in the factor analysis of the Raven's score, the Numeracy score, and the score in the Hit 15 game (see also Burks et al. (2009)). ${ }^{6}$ The five personality trait measures that we have derived are normalized in the unit interval. In the sample, they have an approximately normal distribution, with slight negative skew, with mean between 0.4 and 0.7 , and SD between 0.11 and 0.30 .

\section{Experimental results: Relating Personality and Economic Preferences}

In all the regressions reported below we control for all the variables described in Section 2.1, Socio-economic Characteristics.

\subsection{Correlations}

First in our list of questions to investigate is the link between economic preferences and personality traits. The analysis below extends that of Burks et al. (2009), where only cognitive skill was considered, to the entire set of Big Five factors. Table 1 below reports the pair-wise correlation coefficients between the variables. The significance ( $p$-value) of the coefficient is reported in italics below the coefficient.

\section{Insert Table 1 here}

The data confirm that there is an unconditional correlation between all the main measurements of economic preferences and Openness/Intellect (measured here by CSI). The correlation is positive for willingness to take risks in the Gain domain and

\footnotetext{
${ }^{5}$ This game is also studied in Gneezy, et al. (2010)

${ }^{6}$ There was a problem with the Hit15 task that caused us to lose approximately the first 150 data points, which is why the $\mathrm{N}$ drops when we use it.
} 
willingness to accept delays in payment, and negative for risk acceptance in Losses. There is a weak negative correlation between Neuroticism and Risk acceptance in gains, and a stronger one between Agreeableness and Acceptance of delay. The first is natural but weaker than we might expect; the second could be the consequence of trust in the experimenter; alternatively, aggression could be genuinely associated with high impatience due to impulsivity and unconcern about long-term consequences of actions. In order to get a clearer picture, we have to refine our analysis. In the regressions reported below, all the variables except Age and $\mathrm{Age}^{2}$ (which are in years) are normalized to be in the range zero to 1 , so the size of the coefficients are comparable.

\subsection{Personality and Economic Preferences: Attitudes to Risk}

In the regression of Risk Acceptance on personality traits and the control variables (see Table 2), we see that among the personality variables, Neuroticism has a significant effect in the expected direction of reducing the willingness to take risks (around $-0.16, \mathrm{p}=$ 0.009). Conscientiousness weakly affects the attitude to risk through its inhibitive side ($0.1, p=0.096)^{7}$

\section{Insert Table 2 here}

The variable Risk acceptance we have considered so far is an average measure of the attitude to risk of the individual, across both gains and losses, and with higher and lower stakes. If we consider separately the role of gains and losses, the conclusions become both richer and clearer: see the first two columns of Table 3.

\section{Insert Table 3 here}

The overall negative effect of Neuroticism on the willingness to take risks appears to derive mostly from the effect on risk attitude in the gain domain $(-0.2, p=0.003)$, and is weaker in the loss domain. Cognitive skills have a stronger effect in the loss domain: higher CS reduce risk acceptance with losses $(-0.15, \mathrm{p}=0.006)$.

\footnotetext{
${ }^{7}$ Demographic variables used as controls for sample characteristics show up as statistically significant in a number of our regressions. However, because we are primarily concerned with what our sample can tell us about the relationship between personality-theoretic and decision-theoretic variables, and we already have a long and complex story to tell, with the exception of some comments in footnotes we omit specific discussion of control variable effects.
} 
A different approach is to consider a measure of risk aversion based on a power specification of the utility function, instead of the average number of times a lottery is chosen. We restrict here the analysis to choices in the gain domain, as it requires further assumptions to identify utility over the gain-loss boundary. To study the potential effect of stake size (limited, of course, by the modest range in stake variations available), we also consider separately choices with higher and smaller stakes. The coefficient of risk aversion is on average in the sample 0.57 for the higher stakes, and slightly smaller (0.25) for the smaller stakes. The results for this non-linear transformation of the previous measure are substantially similar: Neuroticism has a strong and significant effect, and cognitive skill also has a positive effect.

\subsection{Personality and Economic Preferences: Attitudes towards Ambiguity}

A measure of ambiguity aversion which is independent of risk aversion is hard to specify. An easier measurement is that of the possible additional aversion to (or preference for) uncertain options when the probability of outcomes is not precisely defined. In our data the measure can be obtained as the difference between the number of times the subject chose the lottery (as opposed to the fixed payment) in the risky choice task, on the one hand, and the number of times the subject chose the lottery for the otherwise identical ambiguous choice task, on the other. A larger number of lottery choices in the risky choice task as compared to in the ambiguous choice task can be taken as an index of higher ambiguity aversion; so the variable, called Difference RA, is an index of ambiguity aversion. The variable is approximately normally distributed, with mean close to 0 ( 0.45 , with a range from of -24 to 24$)$, $S D=5.82$, skewness $=0.13$. Regression analysis is presented in Table 4.

\section{Insert Table 4 here}

The only personality trait that has significant effects is Extraversion, which higher score associated with smaller ambiguity aversion. The coefficient is -.08 , with a p-value of .027, and the implied effect for a change from no Extraversion to full Extraversion is around -4 (change in the number of times the lottery is chosen), out of a total of 48 choices

\subsection{Personality and Economic Preferences: Time Preferences}


Our simple measure of willingness to wait for delayed payments is the fraction of delayed payments that the subject chose over the total number of choice.

\section{Insert Table 5 here}

Cognitive skills, as measured by our index, are the only personality characteristic associated with a larger willingness to wait for larger future payments. The variable CSI has a coefficient of 0.343 ( $p$-value $<0.0001$ ); this translates to about 3 and about 9.5 more times the later payment is accepted. ${ }^{8}$

\section{Insert Table 6 here}

As in the case of the attitude to risk, the results are robust to different measures of the willingness to wait. In the first two columns of Table 6 we examine separately the estimates for choice where the earlier payment is immediate and those in which it is not. In the last two columns of Table 6 we report the effects of our control variables on the two parameters, $\beta$ and $\delta$, of a model using a quasi-hyperbolic specification of the utility function (Laibson 1997). In this model, both parameters are discount factors, but $\beta$ measures the willingness to wait when the earlier of the two payments is immediate, and the $\delta$ the same willingness but when both payments are in the future. Hence $\beta$ is a better measure of the impulsivity component of impatience. We observe that effect of cognitive skills is stronger on the $\beta$ parameter by an order of magnitude. There may be a nonlinearity or an interaction effect here, as the finding with a simpler version of this model using the same data in Burks, et al. (2009) was that the effects of CSI on $\beta$ and $\delta$ were qualitatively similar.

\subsection{Personality and Economic Preferences: Summary}

In summary, our analysis strengthens the conclusion derived from the correlation analysis: the main effects of personality traits on economic preferences are the positive effect of cognitive ability on Delay Acceptance and the negative effect of Neuroticism on Risk Acceptance.

\section{Experimental Results: behavior in strategic setting}

\footnotetext{
${ }^{8}$ Interestingly, although education is not always significant when cognitive skill is, in this case education and CSI are both significant, confirming the view that education teaches patience, other things equal.
} 
One of the experimental tasks was a sequential Prisoner's Dilemma (PD) game. Two players are endowed with \$5 each, and move one after the other. The first decides whether to transfer $\$ 0$ or $\$ 5$ to the second. The second player is informed of the move of the first, and decides how much to transfer back, selecting the amount from the set $\{0$, $1, \ldots, 5\}$. The amount chosen by each subject is doubled by the experimenter before receipt by the other. ${ }^{9}$ Choices of the subjects were elicited by the strategy method: each subject had to decide how much he would transfer as first player, and also how much he would transfer back as second player, for each of the two cases of a \$0 and a \$5 transfer by the first player.

Before actual choices were made, the beliefs of the subjects about the moves of the others were elicited: subjects were asked what percentage of subjects would transfer \$5 as first movers ("What percent of the participants do you think will send their \$5?”), and the average amount that would be sent back as second players, in the two different cases ("If Person 1 does send \$0-respectively, \$5-what is the average amount that participants in this room will send back?”). The results of regressing beliefs on the demographic controls, economic preferences, and personality traits are reported in Table 7.

\section{Insert Table 7 here}

A higher score in Cognitive Skills increases the predictions by subjects of the percentage of subjects that will send the $\$ 5$ transfer as first movers (by 20 per cent, $p$ value $=0.001)$, decreases the amount predicted to be transferred after a $\$ 0$ transfer, and increases that predicted by subjects after the $\$ 5$ transfer. Personality traits also matter. In addition, Agreeableness increases the fraction of first movers subjects predict to transfer $\$ 5$ (by 18 per cent, $p$-value $=0.013$ ), and the average amount predicted to be transferred after a $\$ 5$ transfer is received $(0.85, p$-value $=0.03)$. Neuroticism shows weak evidence of increasing the amount predicted to be returned by the second mover irrespective of the amount received from the first mover.

\section{Insert Table 8 here}

\footnotetext{
9 This distinguishes the sequential PD from the Trust Game, in which only the transfer from the first mover to the second is increased by the experimenter.
} 
Next we look at what subjects actually sent. We examine the three decisions separately with a set of nested regression models. We start with just the demographic controls, then add just the personality traits, then just the economic preferences, and then both (first with unitary Conscientiousness, and then with Conscientiousness as two distinct facets). We focus on the estimated coefficients from the most complete model. Economic preferences have mixed effects: the amount transferred as first player increases $(0.19, p$-value $<0.01)$ in subjects with higher willingness to take risks and with greater patience $(.11, \mathrm{p}=.05)$; this may be expected since the response of the second mover is unknown, hence risky, and there is a short delay in discovering the response of the second mover. But when we look at second mover behavior, we see that risk tolerance also increases the amount sent as irrespective of the amount received (coefficients of .92 and .75, both significant at better than 1\%), and patience increases the amount sent back when $\$ 5$ was received (.51, $\mathrm{p}=$ value .021) but not when $\$ 0$ was received. This is less expected, since as second mover subjects can expect no response from the first mover.

\section{Insert Table 9 here}

As far as personality traits, cognitive skills increase the amount returned as second mover when $\$ 5$ was received (.87, p-value $=.026)$, and more strongly reduce the amount returned after $\$ 0$ was received $(-1.47$, p-value $=.000) .{ }^{10}$ Agreeableness increases the amount sent in all roles, as first mover (.51, p-value .000), as second mover after receiving $\$ 0$ (1.54, p-value .040), and also as second mover after receiving \$5 (1.65, pvalue .000). The fact that Agreeableness has about the same effect on returns after receiving both $\$ 0$ and $\$ 5$ suggests an interpretation as an indicator of pure altruism. The amount sent as second mover increases with Neuroticism in the case of the low transfer (1.04, $p$-value $=0.040)$ and weakly in the case of the high transfer $(.78, p$-value $=.096)$ from the first player. Finally, there is weak evidence that the proactive or achievementoriented side of Conscientiousness reduces both the amount sent as first mover and the amount returned as second mover after receiving $\$ 5(-.18$, p-value $=.084)$.

\footnotetext{
${ }^{10}$ We don't here find the positive effect of cognitive skills on first mover sending observed for IQ in Burks, et al. (2009), but that is likely due to the fact that the effect observed there was non-linear, and we maintain a linear specification here for comparability with other regressions, and also the fact that we lose 150 observations in moving from IQ to CSI, as mentioned above in Section 2.4.
} 


\section{Insert Table 10 here}

\section{Economic Outcomes: Credit Score}

The credit score is the FICO-98, purchased by the trucking company from the Fair Isaac Corporation. It is available because each trainee signed a contract that is legally a credit agreement, which commits them to repay the commercial cost of the training if they do not complete one year of service after training (see Section 10, Appendix). 942 of the trainees had a credit score. The credit score in this group has a distribution over nearly the full nominal range of possible scores (407 to 821 out of a nominal range of 300 to 850 ), with a mean of 588.4, SD $=93.2$, and median 567. The national median value was around 723 at the time of the data collection (Board of Governors 2007), and the subprime level of creditworthiness starts somewhere between 600 and 650 on the FICO-98. ${ }^{11}$ The other subjects were reported to have insufficient identifiable data in their credit record to permit the computation of the FICO -98 .

The distribution is not normal or log-normal: the log of the variable is skewed left (skewness 0.29) and flatter than the normal (kurtosis =2.18). An estimate of the factors affecting the Credit Score is reported in Table 11.

\section{Insert Table 11 here}

The association of demographic variables with credit scores is shown to be important in the extensive analysis provided in the report of the Board of Governors of the Federal Reserve to the Congress (2007), and we control for them here. ${ }^{12}$ Several personality traits have an effect Cognitive skill increases credit score but with weak statistical significance (34.65, p-value of .077). Neuroticism has an effect that is of similar significance and size, but negative $(-39.75$, p-value $=.094)$. However, Extraversion has a sizeable effect in the expected direction that is statistically stronger

\footnotetext{
${ }^{11}$ Specific lenders define the credit score cut-off for prime versus subprime differently, and there is no single official definition; see, for example, the definition of 620 at a car buying web site Edmunds.com (Clarke 2001).

${ }^{12}$ Age increases the score by a point per year of age ( $p$-value is around 10 per cent), but the marginal effect is significantly increasing (coefficient of $\mathrm{Age}^{2}$ is $0.07, p$-value $<0.005$ ), so overall at the mean age the effect is two points per extra year. Being divorced decreases it by around 20 points ( $p$-value $<0.008$ ). College education (BA or more) increases it by around 30 to 50 points ( $p$-value $<0.02$ ); lower levels of education have insignificant impact. Note that gender, and all ethnic groups except African-American, have no significant effect once we introduce our personality and economic preference variables.
} 
(-75.54, $p$-value $=0.010)$. If we examine the effect of the unitary higher-order trait of Conscientiousness, it is significant and negative: higher Conscientiousness is associated with a lower Credit Score. The effect is large and significant (-51.28 points, $p$-value $=$ 0.034). Since Conscientiousness is an index of diligence and responsibility the result appears at first sight paradoxical. To explain it, one needs to remember the two aspects of Conscientiousness introduced earlier, and introduce them in the analysis. Once we analyze the effect of the two sides separately, the effects of these two aspects on Credit Score are natural. The proactive side, as a measure of need for achievement, has a negative effect (57.437, $p$-value $=0.013$ ), as one might expect since the need for achievement might induce a pattern of expenses somewhat larger than the individual's means; the scrupulous and cautious side influences the score positively, although not significantly $(39.6, p$-value $=0.117)$.

Among the economic preferences, Risk Acceptance is not significant. Delay Acceptance has a sizeable effect however, and in the expected direction (35.58, $p$-value $=0.001)$.

Both sets of variables pass the Likelihood Ratio (LR) test. If we take the model with the control variables including the education as the null, then the LR test of the

hypothesis that the coefficients of Economic Preferences are zero has a $\chi^{2}=14.99$ ( $p$ value $=0.0006$ ); the same test for Personality Traits has $\chi^{2}=24.26$, $p$-value $=0.0002$.

\section{Insert Table 12 here}

We next ask: should we understand the results for the value of the credit score to be conditional on having a credit score? To answer this we check in Table 12 whether any of our personality or decision-theoretic variables of interest predict having a credit score. While some of our control variables substantially affect the availability of the credit score, we see no effects from the variables of interest. Thus, , it does not appear we need to think of the results for personality traits and economic preferences about the value of the credit score as being conditioned on having a credit score.

\section{Economic Outcomes: Job Attachment}

In this section we investigate the factors affecting separations from the firm. Recall that there is a significant financial penalty to early exit: the trainee will owe the full 
commercial value of the training received if he or she separates--for any reason--from the firm before completing a year of post-training service. We examine exits broken out in several ways, because different exit types may be associated with different personality traits or economic preferences. The first distinction is on the basis of the time at which separation from the firm occurs.

\subsection{Time of separation}

Hiring occurs at the end of the two week basic training program at the training facility, and our intake data is collected halfway through this two-week period. A Training Exit is an exit before the end of basic training, for whatever reason. A Job Exit is an on-the-job separation after hiring, for whatever reason. We estimate a Cox proportional hazard model, in which the hazard rate (the instantaneous rate of failure at time $t$, conditional on surviving until $t$ ) has a baseline component common to all subjects, which is then increased (shifted up) or decreased (shifted down) by an exponential of a linear function of the independent variables and the estimated parameters. ${ }^{13}$ We report the hazard ratio for each variable, so a value of less than one decreases the hazard of exit (implying longer tenure), a value of one means that the variable has no effect, and a value greater than one increases the hazard of exit (implying longer tenure).

\section{Insert Table 13 here}

For Training Exits, economic preferences do not have significant effects (for example our measure of impatience for monetary payment in time, Delay Acceptance, has $p$-value $=0.71$.) However, Cognitive Skills substantially reduce the hazard (hazard ratio $=0.21$, $p$-value $=0.014)$. Also the proactive side of Conscientiousness has a statistically weak effect, reducing the hazard (hazard ratio $=0.24, p$-value $=0.066$ ), while the inhibitive side is not significant ( $p$-value $=0.155$ ). Neuroticism also has a statistically borderline

\footnotetext{
${ }^{13}$ More carefully, the hazard rate for a subject is the product of a baseline hazard function common to all subjects with an exponential of a linear function of that subject's variable values times the estimated parameters. Because the baseline hazard is not parameterized, but given by the data, it can have whatever time path the data provide, which increases the robustness of the model. In Burks, et al. (2008) it is shown that the baseline hazard for new-to-the-industry drivers at this firm increases when the driver first works in his or her own, and then declines until the end of the training contract, when it sharply increases again.
} 
but quantitatively very large effect (hazard ratio $=4.17, p$-value $=0.072$ ). ${ }^{14}$ The training environment includes classroom work, time in a truck simulator, and actual practice in a real tractor-trailer. It is not surprising that cognitive skills matter as they should affect all processes of learning. Neuroticism may be important because the training setting involves high stakes for these new-to-the-industry students: the trainees are subject to the training contract, with its financial penalty for early exit, and they are learning skills for a complete change of their work life and environment. The instructors continuously provide feedback on trainee performance, and those with a particular sensitivity to negative feedback and stress may thus get fired or quit at a higher rate during training.

\section{Insert Table 14 here}

The picture is similar for the case of Job Exits: economic preference have no predictive power, but cognitive skills are a substantial predictor of longer tenure (hazard ratio of $.40, \mathrm{p}=.003$; further comments on this below). A substantial difference from the early exit recorded by Training Exits is the effect of Neuroticism: for the driver trainees that make it from school into a truck a higher score in Neuroticism does not induce a higher risk of job exit. This is sensible if we consider the selection effect, the fact that many with high sensitivity to negative feedback have already exited. In addition, since the driver has succeeded at training, he or she is now less closely supervised and negative feedback for failure is less systematic and more external.

\subsection{Reason for Separation}

The second distinction we address is the basis for separation from the firm. There are two reasons for this to occur: Discharge or Voluntary Quit, in both cases examined only during the first eleven months of job tenure. While a few drivers may quit because they expect to be fired, these two outcomes result from different social processes. Because this is a high-turnover setting, the firm is always interested in retaining drivers. Thus, being discharged indicates a clear failure to meet specific performance standards, such as failing to meet customer-mandated delivery times too frequently. Quitting before the training contract is up (before one year) represents a decision that is in most cases

\footnotetext{
${ }^{14}$ Some of the socio-economic variables, such as African-American (hazard ratio $=2.7, p$-value $<0.0001$ ) and Asian (hazard ratio $=6.7, p$-value $=0.015$ ), induce a large increase in the probability of exit. None of the other socio-economic variables does, including gender, and education.
} 
financially irrational: however bad the job is, sticking it out until the end of one year is for most drivers the dollar-maximizing strategy.

\section{Insert Table 15 here}

\section{Insert Table 16 here}

The personality characteristic that affects substantially both quits and discharges is Cognitive Skills. The reduction is particularly large in the case of Discharges (hazard ratio $=0.13, p$-value $<0.001$ ), but in the case of voluntary quits too the reduction is by half (hazard ratio $=0.48, p$-value $=0.022$ ). This is consistent with the findings of Burks et al. (2009). ${ }^{15}$ The interpretation offered there is still sensible. Cognitive skills affect the ability of the driver to effectively manage his or her work life on the road. Pay is by piece rates (cents per mile for a standard number of miles associated with each trip). So the goal is to select and follow a sequence of routes over hundreds or thousands of miles to meet customer pickup and delivery schedules over the course of several days at a time, and there are many binding constraints on current choices (such as hours of service rules, limitations on where fuel stops may be made, road segments that are prohibited, congestion, and weather conditions), some of which vary stochastically with time. Cognitive skills affect the ability to avoid performance failures leading to discharges, and the ability to complete sufficient trips to earn enough to decide not to quit.

\section{Non-Economic Outcomes: Driving Accidents}

Large truck accidents are inherently statistically difficult to analyze with conventional government data, since ones that are significant enough to report to the Department of Transportation are of quite low incidence, in the range of one or fewer per one hundred million miles travelled (Burks, Belzer, Kwan, Pratt and Shackelford 2010). ${ }^{16}$ However, the cooperating firm keeps administrative records on all incidents in which any damage to a vehicle or a person occurs, and analysts at a captive insurance firm classify each one as preventable (due to a mixture of risk exposure and driver

\footnotetext{
${ }^{15}$ In both cases, minorities have a higher risk; note that the number of African-American subjects in the sample was reasonably large.

16 "DOT reportable" accidents are defined as: An occurrence involving a commercial motor vehicle on a public road in intrastate or interstate commerce, which results in: 1) a fatality; 2) injury to a person requiring immediate treatment away from the scene of the accident; or 3) disabling damage to a vehicle, requiring it to be towed.
} 
decisions) versus non-preventable (due only to risks outside the driver's control). In addition the firm's safety mangers classify accidents according to their potential severity, not just their actual severity, which increases the $\mathrm{N}$ of accidents that represent serious outcomes for the driver, since the potential severity of an accident, in addition to its severity, enters into disciplinary decisions.

The measure of potential severity takes on values of 5, 15, 30, and 50, in order of increasing severity. Accidents of the lowest level of severity occur most frequently. In the period of time we are analyzing a total of 940 accidents were reported that involve the 947 drivers in our data set who have at least one week of driving after basic training. This is an average of about one per driver, but 467 (49\%) of all drivers in the study had no reported accidents, while 235 (25\%) exactly one accident, and the remainder (26\%) had more than one accident, so the distribution is uneven.

Of the total of 940 accidents, 73 per cent were in the lowest level 5; 23 per cent in level 15, 3 per cent in level 30, and only one accident ( 0.1 per cent) at the most serious level 50. (Thus, accidents that are serious enough to be of public safety concern are only about 3\% of the total.) Examples of the lowest potential severity accidents (level 5) are hitting a fixed object (25 per cent of the cases for this level), hitting a parked vehicle (22 per cent), getting stuck and needing a tow to get back on the road (10 per cent), damaged equipment (10 per cent), damaged property of a third party (8 per cent). Examples of the next-to-highest severity (level 30) are overturning (16 per cent), jackknife (13 per cent), being forced off the road by a third party (13 per cent), forcing a third party off the road (3 per cent). The single accident in the highest level was hitting a pedestrian. Only 83 of the total reported accidents were Department of Transportation (DOT) reportable, and so would show up on Federal government records.

In our analysis we focus on the broadest category of preventable accidents. In work not presented here we have analyzed the predictors of accident risk for a large subset ( $N>10,000)$ of the firm's drivers using the demographic, operational, and job-type factors routinely collected in the firm's human resource and operational information technology systems, from which we have determined which variables in our data are relevant for 
measuring exposure to the risk of an accident. ${ }^{17}$ The data we now use are in form of a panel consisting of one observation per driver per week of work, and we have values for all the relevant exposure control variables for each week, thus allowing the level of exposure to vary from week to week.

In Table 17 we report the results of a set of nested Cox proportional hazard rate models of the probability of having a preventable accident of any potential severity. Each of these models includes as predictors all of the characteristics of the job that can in principle affect the level of accident risk to which the driver is exposed. Example variables are the number of miles driven in a week, the number of trip segments completed in a week, and variables that identify the type of work to which the driver is assigned, and the geographic home base location from which the driver works. ${ }^{18}$ The first column adds only our standard human-capital-type demographic controls, the second adds the Big Five alone to demographic controls, the third adds economic preferences alone to the demographic controls, and the last two add both Big Five and economic preferences, the first with a single Conscientiousness factor, and the second with a two-facet version of Conscientiousness.

\section{Insert here Table 17}

Economic theory predicts an effect on the probability of accidents from the attitude towards risk of the individual, either directly (as a personal character trait), or through the effect of personal and family conditions. However, the direct effect of risk aversion in monetary payments (our Risk Acceptance measure) has no predictive power for accidents. Also the measure of impulsivity provided by the estimated discount $\beta$ has no effect. It appears that either there is no generalization across small monetary risks or

\footnotetext{
${ }^{17}$ One unpublished result from this related analysis is that having a preventable accident of the lowest severity level is a positive predictor, controlling for demographics and operational risk factors, for having a later accident of higher severity.

${ }^{18}$ Because work assignments are made by the firm, variables measuring work characteristics such the miles per week, the trip segments per week, and the type of work, to a first approximation are measures of the way the driver's risk of an accident varies due to exogenous factors. For instance, drivers working in "dedicated service" exclusively service a particular large customer, which reduces the number of unfamiliar routes they face, compared to running the system, or being randomly dispatched from one customer to another. Various types of dedicated service cut the risk of a preventable accident to between $40 \%$ and $67 \%$ of the baseline level (which is for the reference category of running the system). This is qualitatively similar to the reduction from the inhibitive facet of Conscientiousness (39\%). The "risk-
} 
delayed payments to actions while driving, or possibly there is an indirect connection acting through the single-never-married marital status. ${ }^{19}$

However, one of the personality traits, the inhibitive side of Conscientiousness, induces a large and significant reduction of the risk (hazard ratio 0.394, ( $p$-value = 0.008). No other traits have a significant effect. Neuroticism is a natural candidate for a reduction of risk, but it does not, and cognitive skills have no significant effect, either.

\section{Non-Economic Outcomes: Health-Related}

In the last section we report the analysis of variables measured contemporaneously with the other initial intake data which are not directly indices of economic performance, but are considered an indication of the general level of health of a person: the Body Mass Index (BMI) and smoking habits.

\subsection{BMI (Body Mass Index)}

The BMI index is computed according to the formula: BMI $=((703) \mathrm{x}$ Weight)/Height ${ }^{2}$ (given measures in inches and pound). In the sample, the BMI has mean 28.1 and SD of 6.9; the median 27.3. The distribution of BMI is approximately log normal, $($ mean $=3.3, \mathrm{SD}=0.23)$. According to the World Health Organization $(2000)$ standards, the BMI levels of our subjects can be categorized as follows: BMI $\leq 18.5$ "Underweight (3\%)," $18.5 \leq$ BMI $<25$ "Normal (32.8\%)," $25 \leq \mathrm{BMI}<30$ "Overweight (31.5\%)," $30 \leq$ BMI < 35 “Obese-Class I (19\%)," $35 \leq$ BMI < 40 "Obese-Class II (6.7\%)," and $40 \leq$ BMI "Obese-Class III (7.9\%)." This distribution is typical of adult subjects in the U.S. during the period of our study (Flegal, Carroll, Ogden and Curtin 2010). Regression results are presented in Table 18.

\section{Insert Table 18 here}

. Extraversion has a significant and positive effect $(0.08, p$-value $=0.036)$. The higher-order unitary Conscientiousness trait has a significant and negative effect, in that higher Conscientiousness improves the BMI Index: standardized coefficient -0.16 , $p$ -

exposure-only" version of this model for the drivers analyzed herein is available from the authors upon request.

19 The only ethnic category that is significant is Native American, but there are too few individuals (29) in this category for this to tell us much. Education has no effect, and the only demographic category that 
value $<0.0001)$. When we analyze the contribution of the two facets of Conscientiousness (inhibitive and proactive) the strongest effect is induced by the proactive side $(-0.21, p$-value $<0.005)$, whereas the inhibitive side has no significant effect $(.03, p$-value $=0.436)$. Among economic preferences Delay Acceptance is a natural candidate and has been used to predict BMI, and has here a borderline significant effect (standardized coefficient 0.07, $p$-value $=0.074$ ). If we take the model with the control variables including the education as the null, then the LR test of the hypothesis that the coefficients of Economic Preferences are zero has $\chi^{2}=6.11$ ( $p$-value $=0.047$ ); the same test for Personality Traits, $\chi^{2}=24.56, p$-value $=0.0002 .^{20}$

\subsection{Smoking Addiction}

A second important behavior that personality traits can help predict is whether the driver trainee smokes. The training is in a short-term residential format, so the firm provides hotel rooms to trainees and therefore keeps track of the room reservations. A subject is classified as smoker if he chose a "smoking” room, and as a non-smoker if he chose a "non-smoking” room; a missing observation is created in all other cases. Table 19 reports the results of the analysis of the factors affecting whether a trainee smokes or not.

\section{Insert Table 19 here}

Among the economic and personality variables, two stand out. A higher score in Delay Acceptance reduces, and a higher score in Risk Acceptance increases, the probability of being a smoker. Here, unlike in the case of vehicle accidents, the two economic preference measures constructed using small to medium monetary rewards appear to generalize across domains. In addition, the Inhibitive facet of Conscientiousness stands out as being associated with reducing the chance of smoking. The marginal effects of these three factors are qualitatively similar: a reduction of 0.27 for Delay Acceptance ( $p$-value < 0.005), an increase of .21 for Risk Acceptance (p-value

matters, is being single and never married. This is related to the effect of this predictor on discharges, since a significant reason for discharge is having too many preventable accidents.

${ }^{20}$ Among the socio-economic and demographic variables, Age (standardized coefficient $=0.19, p$-value $=$ $0.008)$ and Age $^{2}(-0.24, p$-value $<0.001)$ have significant effects; but Education has no effect 
$=.021$ ), and a reduction of 0.36 for the Inhibitive side of Conscientiousness ( $p$-value $=$ $0.026) .{ }^{21}$

If we take the model with the control variables including the education as the null hypothesis, then the LR test of the hypothesis that the coefficients of Economic Preferences are zero has $\chi^{2}=15.97$ ( $p$-value $=0.0003$ ); the same test for Personality Traits, $\chi^{2}=8.35, p$-value $=0.138$. Cognitive skills are the insignificant in the full regression, and their explanatory power is completely absorbed by time preferences.

\section{Discussion}

The large data set analyzed here has the specific advantage of providing data simultaneously on economic preferences and personality traits, as well as a set of important personal characteristics and individual life outcomes. This allows a systematic examination of two directions of analysis: first of the link between the two sets of explanatory constructs, and second the comparison of the effects of personality traits and economic preferences on outcomes, particularly social and economic ones.

We find support for a parsimonious set of hypotheses that simplifies considerably the relationship between economic preferences and personality traits. Several of the links we have found confirm earlier results, but by considering systematically the relation between the measures of personality and preferences, using similar regression models on the same set of subjects, we have been able to test whether other possible links had been overlooked.

The main channel between personality traits and economic preferences goes through Intelligence and Neuroticism. Intelligence affects the preferences over time of delivery of rewards, increasing patience. This effect seems to be almost exclusive: other traits do not affect time preferences, as typically measured by economists. Higher education does increase patience, and it is likely to be positively correlated with intelligence, but the effect of the latter is significant even after we control for education. If we distinguish between short run and long run impatience (as in quasi-hyperbolic models (Laibson, 1997) then intelligence affects both, although the effect on short run impatience is larger.

\footnotetext{
${ }^{21}$ Some of the effects among the socio-economic variables are natural and expected. Education reduces the probability of smoking (the marginal effect with respect to the baseline (a High School degree). Having a BA or more reduces by 17 per cent ( $p$-value $<0.027$ ), some college by 10 per cent ( $p$-value $<0.031$ ).
} 
Neuroticism affects attitude to risk, decreasing willingness to take risks. As we noted, this result is in line with several previous findings connecting Neuroticism to a general adversity to uncertainty (Hirsh et al., 2008). Intelligence modulates the preferences over risky choices by reducing the difference in risk aversion between gain and loss domains, hence making the overall preference over risky outcomes more consistent.

Other personality traits enter into finer details of economic preferences. Extraversion modulates the aversion to ambiguity, reducing the specific aversion to options where the probability of outcomes is not clearly defined. A possible interpretation of these results is that Extraversion is associated with a more optimistic view (Sharpe, Martin, \& Ross, 2011), which biases the individual toward expecting the more favorable possible probability because of a greater sensitivity to the possibility of reward.

An important and natural hypothesis in the integration of decision theory and personality theory is that Agreeableness affects only behavior that is specifically social. This restriction on the scope of the trait is explicit in models in which the four regulatory functions associated with the other traits are sufficient for an individual living in isolation, but Agreeableness is needed for the specific requirements of life in society (DeYoung, 2010b; Van Egeren, 2009). The converse is of course false: the other four traits may have important roles in social life, as interactions with others affect the probability of rewards or punishments induced by our actions, as well as their delivery in time. Our findings support these hypotheses. Agreeableness plays an important role in both cognitive and behavioral responses in our experimental game (the sequential prisoner's dilemma). The effect on social cognition is clear in that Agreeableness predicted beliefs about the action of others; a higher score is associated with an inclination to expect more cooperative behavior. This expectation is unconditional-that is, significant even independently of the action of others (as can be seen, for example, in that Agreeableness predicted trust by the first player and reduced the second player's dependence on the choice of the first player in deciding whether to give money back). The only other variable on which Agreeableness has a weak effect is smoking habit. Given that smoking has some consequences for others (usually considered unpleasant), this effect is also coherent with the view that this trait regulates social behavior. 
Economic preferences do play an important role in social interactions. For example, willingness to take risks and patience increases the willingness to trust others, as is the case for people who choose a positive initial transfer in our game. This is to be expected; in our data, a higher transfer by the first player is associated with a propensity of the second player to return a higher amount. Thus, trusting others in this game corresponds to the choice of a riskier option with higher expected return, and hence a positive transfer is positively correlated with willingness to take risks.

An important contribution of this research is the finding that adding personality assessments to the typical demographic and human capital measures used by economists, and to experimental measurements of economic preferences, increases predictive power significantly for most dependent variables, and especially that this holds true in the cases in which our dependent variables are real-world economic outcomes. Of course, adding to the list of independent variables can never decrease the predictive power of a statistical model, but introducing personality traits appears to give a substantial increase in the ability to explain economic behavior. Further, we find that when we compare the explanatory power of the two sets of variables, they are at least similar in size, or that of personality variables is larger.

Our data confirm that intelligence, here conceived as a crucial component of the Openness/Intellect trait domain, has a strong positive effect on most outcomes: credit score, job persistence, and Body Mass Index (the exception is truck accidents). These effects are in all cases not attributable to the higher education associated with higher intelligence, as education is always one of the control variables. Conscientiousness is second only to intelligence in the positive effect on several outcomes: in our data, these include outcomes as diverse as fewer driving accidents and job persistence. Despite its importance for economic outcomes, and unlike the other four of the Big Five, Conscientiousness is difficult to relate empirically to standard economic models of choice; hence, it is likely to be the trait at the center of future investigations.

Once we have clarified that personality variables affect economic outcomes, a new direction of research is open: to determine how the effects operate. Our results indicate that this may occur in surprising ways, suggesting that a deeper understanding of this connection is needed. The example of the negative effect of Conscientiousness on Credit 
Score, resulting from a weak or insignificant positive effect of the Inhibitive facet and a strong and negative effect of the Proactive one, suggests that these connections may be complex.

For future research addressing such complexity, several directions seem essential. First, there is currently a methodological divide between elicitation of personality traits (based on survey questions, usually providing self-ratings) and economic preferences (based on incentivized choices). A homogeneous method of elicitation for the two sets of individual characteristics is desirable, to make the study of the link and comparison between the effect sizes of the two more precise. Second, formal models in the theory of personality, comparable to those available for decision theory, are necessary. If elicitation is based on choices, then the classical problem of decision theory arises, namely deriving well-defined individual characteristics from observed choices, for which a formal theoretical framework is important. Finally, a better understanding of the mechanistic basis of both choice activity and personality is needed, based on recent progress in understanding the neural basis of choice (see e.g. Mohr et al. 2010 for a review) and personality (DeYoung, 2010a; DeYoung \& Gray, 2009). In all future research, we believe that greater progress will be made by integrating personality and decision theory in order to better utilize the strengths of both.

\section{Appendix A: Who are the subjects?}

The cooperating firm operates in the "full truckload" (TL) segment of the U.S. for-hire motor freight industry. TL drivers provide point-to-point service within a region or across the continent, but normally within the U.S. They are paid by the mile to operate large tractor-trailers (maximum gross vehicle weight of $80,000 \mathrm{lbs}$., or $36,000 \mathrm{~kg}$, and an overall length of 60 to 65 ft., or about 20 meters). TL drivers generally drive medium to long distances, work relatively long and irregular weekly hours, and have limited and often uncertain amounts of time off at home. The salient characteristics of this segment for economists are that it has very low entry barriers, and few, if any, economies of scale, so it is essentially perfectly competitive (Burks, Belzer, Kwan, Pratt and Shackelford 2010). Thus, firms have very little pricing power, and very little ability to pass higher labor costs through to customers, so the pay rates are modest. 
The resulting labor market equilibrium for TL drivers, stable since the segment emerged in its modern form in the mid-eighties after the 1980 deregulation, involves high turnover, which shows that the costs of high turnover are less than the alternative of paying compensating differentials (or running trucks out of route to get drivers home more often) in order to keep more drivers longer (Burks, Carpenter, Götte, Monaco, Porter and Rustichini 2008). Our initial intake data was collected during the boom years of 2005 and 2006, when, according to the American Trucking Associations, the annualized turnover rate at large TL firms hadn't been under 100\% since they began tracking it. ${ }^{22}$

Like many larger TL firms, during times of economic expansion the cooperating firm actively recruits new-to-the-industry drivers, and trains them at one or more companyoperated schools. Drivers without both a commercial driver's license (CDL) and sufficient recent over-the-road experience go through a two-week residential basic training program, followed by one to four weeks hauling freight with an instructor beside them in the cab, before beginning work entirely on their own. All trainees signed a training contract, the terms of which called for an immediate repayment of the full market value of the training (on the order of $\$ 4,000$ ) if the individual did not complete one year of service after training, for any reason.

We collected our data from trainees at a school in the upper Midwest. Of the approximately 3,000 trainees passing through the school annually we offered the opportunity to take part in the study to 1,178 ; of these 1,069 , or $90.8 \%$, chose to take part. $^{23}$

Interestingly, among our subjects we find that in a forced-choice question asking for a single response, about 50\% report the most important reason they entered training was for lifestyle reasons (e.g. wanted to travel, wanted to drive a big rig, etc.), and only about $40 \%$ gave a directly economic answer (e.g. need a regular job, or like the pay). As a result, despite the high turnover rate, our subject group is unlikely to be composed of

\footnotetext{
${ }^{22}$ The economic recession significantly reduced TL driver turnover: the annualized turnover rate at large TL carriers bottomed out at 39\% in the first quarter of 2010. However, it has been rising again since then (Watson 2010, Watson 2009).
} 
only the economically desperate, and therefore to be fairly broadly representative of the blue collar service-sector workforce in the U.S.

${ }^{23}$ Four trainees received phone calls at the break between sessions requiring them to attend to family matters, or for some other reason did not complete the full data collection process, giving 1,065 as the final subject count. 


\section{References}

Ackerman, Phillip L., and Eric D. Heggestad, "Intelligence, personality, and interests: Evidence for overlapping traits," Psychological Bulletin, 121 (1997), 219-245.

Block, Jack, Personality as an affect-processing system: Toward an integrative theory (Mahwah, NJ, US: Lawrence Erlbaum Associates Publishers, 2002).

Board of Governors, "Report to the Congress on Credit Scoring and Its Effects on the Availability and Affordability of Credit," (Washington, DC: Federal Reserve System, 2007).

Borghans, Lex, Angela Lee Duckworth, James J. Heckman, and Bas ter Weel, "The Economics and Psychology of Personality Traits," Journal of Human Resources, 43 (2008), 972-1059.

Burks, Stephen, Jeffrey Carpenter, and Lorenz Götte, "Performance Pay and Worker Cooperation: Evidence from an Artefactual Field Experiment," Journal of Economic Behavior and Organization, 70 (2009), 458-469.

Burks, Stephen, Jeffrey Carpenter, Lorenz Götte, Kristen Monaco, Kay Porter, and Aldo Rustichini, "Using Behavioral Economic Field Experiments at a Firm: the Context and Design of the Truckers and Turnover Project," in The Analysis of Firms and Employees: Quantitative and Qualitative Approaches, Stefan Bender, Julia Lane, Kathryn Shaw, Fredrik Andersson, and Till von Wachter, eds. (Chicago and London: NBER and University of Chicago 2008).

Burks, Stephen, Jeffrey Carpenter, Lorenz Götte, and Aldo Rustichini, "Which measures of time preference best predict outcomes: Evidence from a large-scale field experiment," Journal of Economic Behavior and Organization, (2012 in press).

Burks, Stephen V., Michael Belzer, Quon Kwan, Stephanie Pratt, and Sandra Shackelford, "Trucking 101: An Industry Primer," in Transportation Research Circular Number E-C146, (Washington, DC: Transportation Research Board, 2010).

Burks, Stephen V., Jeffrey Carpenter, Lorenz Götte, and Aldo Rustichini, "Cognitive Skills Affect Economic Preferences, Social Awareness, and Job Attachment," Proceedings of the National Academy of Science (USA), 106 (2009), 7745-7750.

---, "Overconfidence is a Social Signalling Bias," Institute for the Study of Labor Discussion Paper \# 4840, (2010), 1-43. 
Clarke, Warren, "Tips for Subprime Borrowers; Getting a Car Loan with Bad Credit," in Edmunds.com, (Edmunds Corporation, 2001).

Costa, Paul T., Robert R. McCrae, and David A. Dye, "Facet scales for agreeableness and conscientiousness: A revision of the NEO Personality Inventory," Personality and Individual Differences, 12 (1991), 887-898.

Denissen, Jaap J. A., and Lars Penke, "Motivational individual reaction norms underlying the Five-Factor model of personality: First steps towards a theory-based conceptual framework.," Journal of Research in Personality, 42 (2008), 1285-1302.

DeYoung, C. G., "Personality neuroscience and the biology of traits," Social and Personality Psychology Compass, 4 (2010), 1165-1180.

---, "Toward a Theory of the Big Five," Psychological Inquiry, 21 (2010), 26-33.

---, "Intelligence and Personality," in The Cambridge Handbook of Intelligence, R. J. Sternberg, and S. B. Kaufman, eds. (New York: Cambridge Univeristy Press, 2011).

DeYoung, C. G., R. G. Grazioplene, and J. B. Peterson, "From madness to genius: the Openness/Intellect trait domain as a paradoxical simplex," Journal of Research in Personality, (forthcoming 2012).

DeYoung, C. G., J. B. Hirsh, M. S. Shane, X. Papademetris, N. Rajeevan, and J. R. Gray, "Testing Predictions From Personality Neuroscience: Brain Structure and the Big Five," Psychological Science, 21 (2010), 820-828.

DeYoung, C. G., L. C. Quilty, and J. B. Peterson, "Between facets and domains: 10 aspects of the big five," Journal of Personality and Social Psychology, 93 (2007), 880896.

DeYoung, C. G., L. C. Quilty, J. B. Peterson, and J. R. Gray, "Openness to Experience, Intellect, and cognitive ability," Journal of Personality Assessment, (forthcoming 2012).

DeYoung, C. G., N. A. Shamosh, A. E. Green, T. S. Braver, and J. R. Gray, "Intellect as Distinct From Openness: Differences Revealed by fMRI of Working Memory," Journal of Personality and Social Psychology, 97 (2009), 883-892.

Ellsberg, D., "Risk, ambiguity, and the Savage axioms," Quarterly Journal of Economics, 75 (1961), 643-669.

Flegal, K. M., M. D. Carroll, C. L. Ogden, and L. R. Curtin, "Prevalence and trends in obesity among US adults, 1999-2008," JAMA, 303 (2010), 235-241. 
Gneezy, Uri, Aldo Rustichini, and Alexander Vostroknutov, "Experience and Insight in the Race Game," Journal of Economic Behavior and Organization, 75 (2010), 144-155.

Goldberg, L. R., "An alternative "description of personality": The Big-Five factor structure," Journal of Personality and Social Psychology, 59 (1990), 1216-1229.

Hinson, John M., Tina L. Jameson, and Paul. Whitney, "Impulsive decision making and working memory," Journal of Experimental Psychology: Learning, Memory, and Cognition, 29 (2003), 298-306.

Hirsh, J. B., C. G. DeYoung, and J. B. Peterson, "Metatraits of the Big Five Differentially Predict Engagement and Restraint of Behavior," Journal of Personality, 77 (2009), 10851102.

Hirsh, J. B., and M. Inzlicht, "The Devil You Know: Neuroticism Predicts Neural Response to Uncertainty," Psychological Science, 19 (2008), 962-967.

Hirsh, J. B., D. Morisano, and J. B Peterson, "Delay discounting: Interactions between personality and cognitive ability," Journal of Research in Personality, 42 (2008), 16461650.

Jang, Kerry L., W. John Livesley, Alois Angleitner, Rainer Riemann, and Philip A.. Vernon, "Genetic and environmental influences on the covariance of facets defining the domains of the five-factor model of personality," Personality and Individual Differences, 33 (2002), 83-101.

John, Oliver P., Laura P. Naumann, and Christopher J.. Soto, "Paradigm Shift to the Integrative Big Five Trait Taxonomy: History, Measurement, and Conceptual Issues," in Handbook of Personality: Theory and Research Oliver P. John, Richard W. Robins, and Lawrence A. Pervin, eds. (New York, NY, US: Guilford Press, 2008).

Kahneman, Daniel, and Amos Tversky, "Prospect Theory: An Analysis of Decision under Risk," Econometrica, 47 (1979), 263-291.

Laibson, David, "Golden Eggs and Hyperbolic Discounting," Quarterly Journal of Economics, 112 (1997), 443-477.

Markon, K. E., R. F. Krueger, and D. Watson, "Delineating the Structure of Normal and Abnormal Personality: An Integrative Hierarchical Approach," Journal of Personality and Social Psychology, 88 (2005), 139-157.

McCrae, Robert R., and Paul T. Costa, "Conceptions and correlates of openness to 
experience," in Handbook of personality psychology, Robert Hogan, John A. Johnson, and Stephen R. Briggs, eds. ( San Diego, CA: Academic Press, 1997).

Nettle, Daniel, "The Evolution of Personality Variation in Humans and Other Animals," American Psychologist 61 (2006), 622-631.

Ones, Deniz S., and Chockalingam Viswesvaran, "The effects of social desirability and faking on personality and integrity assessment for personnel selection," Human Performance, 11 (1998), 245-269.

Ostaszewski, Pawel, "The relation between temperament and rate of temporal discounting," European Journal of Personality, 10 (1996), 161-172.

Ozer, Daniel J., and Verónica Benet-Martínez, Personality and the prediction of consequential outcomes (Palo Alto, CA, US: Annual Reviews, 2006).

Rabin, Matthew, and Georg Weizsacker, "Narrow Bracketing and Dominated Choices," American Economic Review, 99 (2009), 1508-1543.

Raven, J., J.C. Raven, and J.H. Court, "Section 3: The Standard Progressive Matrices," in Manual for Raven's Progressive Matrices and Vocabulary Scales, (San Antonio, TX: Psychological Corporation, 2000).

Richards, Jerry B., Lan Zhang, Suzanne H. Mitchell, and Harriet. de Wit, "Delay or probability discounting in a model of impulsive behavior: Effect of alcohol," Journal of the Experimental Analysis of Behavior, 71 (1999), 121-143.

Roberts, B. W., N. R. Kuncel, R. Shiner, A. Caspi, and L. R. Goldberg, "The Power of Personality The Comparative Validity of Personality Traits, Socioeconomic Status, and Cognitive Ability for Predicting Important Life Outcomes," Perspectives on Psychological Science, 2 (2007), 313-345.

Rustichini, A., "Neuroeconomics: what have we found, and what should we search for," Current Opinion in Neurobiology, 19 (2009), 672-677.

Saucier, Gerard, "Benchmarks: Integrating affective and interpersonal circles with the Big-Five personality factors," Journal of Personality and Social Psychology, 62 (1992), 1025-1035.

Schmeidler, David, "Subjective Probability and Expected Utility without Additivity," Econometrica, 57 (1989), 571-587.

Shamosh, N. A., C. G. DeYoung, A. E. Green, D. L. Reis, M. R. Johnson, A. R. A. 
Conway, R. W. Engle, T. S. Braver, and J. R. Gray, "Individual differences in delay discounting: Relation to intelligence, working memory, and anterior prefrontal cortex," Psychological Science, 19 (2008), 904-911.

Shamosh, N. A., and J. R. Gray, "Delay discounting and intelligence: A meta-analysis," Intelligence, 36 (2008), 289-305.

Swann, Alan C., James M. Bjork, F. Gerard Moeller, and Donald M. Dougherty, "Two models of impulsivity: Relationship to personality traits and psychopathology," Biological Psychiatry, 51 (2002), 988-994.

Tellegen, A. , and N. G. Waller, "Exploring personality through test construction: Development of the Multidimensional Personality Questionnaire," in The SAGE Handbook of Personality Theory and Assessment, G. J. Boyle, G. Matthews, and D. H. Saklofske, eds. (London, UK: SAGE Publications Ltd., 2008).

Tellegen, Auke, "Title," University of Minnesota, 1982.

Van Egeren, Lawrence F., "A cybernetic model of global personality traits.," Personality and Social Psychology Review, 13 (2009), 92-108.

Watson, Rick, "Driver Turnover Rate Rises," in Transport Topics, (Alexandria, VA: American Trucking Associations, 2010).

Watson, Rip, "TL Driver Turnover Rates Fall to Historic Lows, ATA Reports," in Transport Topics, (Arlington, VA: American Trucking Associations, 2009).

WHO, Obesity: Preventing and Managing the Global Epidemic (Geneva: World Health Organization, 2000). 


\section{Tables}

Table 1: Correlation among main scales. CS: Cognitive Skill; E: Extraversion; $N$ : Neuroticism; $C$ : Conscientiousness; A: Agreeableness; RAcc G: Risk Acceptance in Gains; RAccL: Risk Acceptance with Losses; DAcc: Delay Acceptance.

\begin{tabular}{l|lllll|ll}
\hline & CS & $\mathrm{E}$ & $\mathrm{N}$ & $\mathrm{C}$ & $\mathrm{A}$ & RAccG & RAccL \\
\hline $\mathrm{E}$ & 0.001 & 1 & & & & & \\
$\mathrm{~N}$ & $(0.661)$ & & & & & & \\
& -0.06 & -0.32 & 1 & & & & \\
$\mathrm{C}$ & $(0.061)$ & $(0.000)$ & & & & & \\
& -0.04 & 0.27 & -0.40 & 1 & & & \\
$\mathrm{~A}$ & $(0.217)$ & $(0.000)$ & $(0.000)$ & & & & \\
& -0.03 & 0.05 & -0.36 & 0.39 & 1 & & \\
& $(0.337)$ & $(0.083)$ & $(0.000)$ & $(0.0000)$ & & & \\
\hline RAccG & 0.10 & 0.007 & -0.05 & -0.01 & -0.04 & 1 & \\
& $(0.001)$ & $(0.81)$ & $(0.059)$ & $(0.561)$ & $(0.108)$ & & \\
RAccL & -0.14 & -0.03 & -0.023 & -0.02 & 0.01 & 0.47 & 1 \\
& $(0.000)$ & $(0.197)$ & $(0.436)$ & $(0.386)$ & $(0.659)$ & $(0.000)$ & \\
DAcc & 0.22 & -0.01 & 0.015 & -0.004 & 0.07 & 0.07 & 0.01 \\
& $(0.000)$ & $(0.596)$ & $(0.731)$ & $(0.898)$ & $(0.018)$ & $(0.019)$ & $(0.732)$ \\
\hline
\end{tabular}


Table 2: Determinants of risk acceptance. The dependent variable is the risk acceptance, (defined as the fraction of lotteries taken instead of the sure amount), in the entire set of risky choices made.

\begin{tabular}{|c|c|c|c|}
\hline & $\begin{array}{r}(1) \\
b / p\end{array}$ & $\begin{array}{r}(2) \\
b / p\end{array}$ & $\begin{array}{r}(3) \\
b / p\end{array}$ \\
\hline \multirow[t]{2}{*}{ Female } & -0.02 & -0.01 & -0.01 \\
\hline & $(0.372)$ & $(0.718)$ & $(0.745)$ \\
\hline \multirow[t]{2}{*}{ African-American } & -0.03 & -0.03 & -0.03 \\
\hline & $(0.203)$ & $(0.178)$ & $(0.288)$ \\
\hline \multirow[t]{2}{*}{ Native American } & $0.10^{* *}$ & $0.10^{* *}$ & $0.09 *$ \\
\hline & $(0.019)$ & $(0.042)$ & $(0.060)$ \\
\hline \multirow[t]{2}{*}{ Asian } & 0.12 & 0.11 & 0.11 \\
\hline & $(0.148)$ & $(0.309)$ & $(0.279)$ \\
\hline \multirow[t]{2}{*}{ Separated } & -0.04 & -0.05 & -0.05 \\
\hline & $(0.307)$ & $(0.279)$ & $(0.219)$ \\
\hline \multirow[t]{2}{*}{ Divorced } & 0.03 & 0.03 & 0.03 \\
\hline & $(0.119)$ & $(0.127)$ & $(0.136)$ \\
\hline \multirow[t]{2}{*}{ Never Married } & -0.00 & -0.01 & -0.01 \\
\hline & $(0.923)$ & $(0.622)$ & $(0.577)$ \\
\hline \multirow[t]{2}{*}{ Age } & 0.00 & -0.00 & -0.00 \\
\hline & $(0.450)$ & $(0.681)$ & $(0.669)$ \\
\hline \multirow[t]{2}{*}{$\operatorname{Age}^{2}$} & -0.00 & 0.00 & 0.00 \\
\hline & $(0.221)$ & $(0.915)$ & $(0.931)$ \\
\hline \multirow[t]{2}{*}{ Some College } & -0.01 & 0.00 & 0.00 \\
\hline & $(0.624)$ & $(0.962)$ & $(0.964)$ \\
\hline \multirow[t]{2}{*}{ BA or more } & $-0.05 *$ & -0.04 & -0.04 \\
\hline & $(0.056)$ & $(0.214)$ & $(0.224)$ \\
\hline \multirow[t]{2}{*}{ Cognitive Skill } & & -0.04 & -0.04 \\
\hline & & $(0.447)$ & $(0.434)$ \\
\hline \multirow[t]{2}{*}{ Extraversion } & & -0.03 & -0.04 \\
\hline & & $(0.670)$ & $(0.577)$ \\
\hline \multirow[t]{2}{*}{ Neuroticism } & & $-0.16^{* * *}$ & $-0.15^{* * *}$ \\
\hline & & $(0.005)$ & $(0.009)$ \\
\hline \multirow[t]{2}{*}{ Agreeableness } & & -0.05 & -0.04 \\
\hline & & $(0.324)$ & $(0.503)$ \\
\hline \multirow[t]{2}{*}{ Conscientiousness } & & -0.06 & \\
\hline & & $(0.313)$ & \\
\hline \multirow[t]{2}{*}{ Inhibitive Side of Consc. } & & & $-0.10^{*}$ \\
\hline & & & $(0.096)$ \\
\hline \multirow[t]{2}{*}{ Proactive Side of Consc. } & & & -0.00 \\
\hline & & & $(0.960)$ \\
\hline \multirow[t]{2}{*}{ Constant } & $0.64^{* * *}$ & $0.82^{* * *}$ & $0.85^{* * *}$ \\
\hline & $(0.000)$ & $(0.000)$ & $(0.000)$ \\
\hline $\mathrm{r} 2$ & 0.018 & 0.027 & 0.029 \\
\hline $\mathrm{N}$ & 1068 & 861 & 861 \\
\hline
\end{tabular}


Table 3: Determinants of risk acceptance with gains and losses, and risk aversion coefficient. RA Gains and RA Losses are risk acceptance (defined as the fraction of lotteries taken instead of the sure amount) in gains and losses respectively. CRA Low and CRA High are the Coefficents of Risk Aversion (CRA) for higher ( expected value 6 dollars) and lower (3 dollars) stakes respectively. The mean values are 0.57 (SE 0.056) for CRA High and 0.25 (SE 0.057) for CRA Low.

\begin{tabular}{|c|c|c|c|c|}
\hline & $\begin{array}{r}\text { RA Gains } \\
\text { b/p }\end{array}$ & $\begin{array}{r}\text { RA Losses } \\
\mathrm{b} / \mathrm{p}\end{array}$ & $\begin{array}{r}\text { CRA High } \\
\mathrm{b} / \mathrm{p} \\
\end{array}$ & $\begin{array}{r}\text { CRA Low } \\
\mathrm{b} / \mathrm{p}\end{array}$ \\
\hline Female & 0.03 & -0.04 & -0.22 & $\begin{array}{r}-0.17 \\
(0.399)\end{array}$ \\
\hline African-American & $-0.07^{* *}$ & $\begin{array}{r}0.02 \\
0.02\end{array}$ & $0.37^{*}$ & $\begin{array}{c}(0.399) \\
0.42^{* *} \\
(0.032)\end{array}$ \\
\hline Native American & $\begin{array}{c}0.12^{* *} \\
(0.040)\end{array}$ & $\begin{array}{r}0.07 \\
(0.221)\end{array}$ & $\begin{array}{r}-0.30 \\
(0.454)\end{array}$ & $\begin{array}{l}-0.88^{* *} \\
(0.026)\end{array}$ \\
\hline Asian & $\begin{array}{r}0.03 \\
(0.784)\end{array}$ & $\begin{array}{r}0.19 \\
(0.113)\end{array}$ & $\begin{array}{r}-0.02 \\
(0.979)\end{array}$ & $\begin{array}{r}-0.28 \\
(0.728)\end{array}$ \\
\hline Separated & $\begin{array}{r}-0.06 \\
(0.180)\end{array}$ & $\begin{array}{r}-0.04 \\
(0.420)\end{array}$ & $\begin{array}{r}0.42 \\
(0.217)\end{array}$ & $\begin{array}{r}0.43 \\
(0.189)\end{array}$ \\
\hline Divorced & $\begin{array}{r}0.02 \\
(0.334)\end{array}$ & $\begin{array}{r}0.04 \\
(0.107)\end{array}$ & $\begin{array}{r}-0.18 \\
(0.319)\end{array}$ & $\begin{array}{r}-0.11 \\
(0.507)\end{array}$ \\
\hline Never Married & $\begin{array}{l}-0.05^{* *} \\
(0.047)\end{array}$ & $\begin{array}{r}0.02 \\
(0.333)\end{array}$ & $\begin{array}{c}0.29^{*} \\
(0.077)\end{array}$ & $\begin{array}{r}0.25 \\
(0.117)\end{array}$ \\
\hline Age & $\begin{array}{l}-0.00^{* *} \\
(0.010)\end{array}$ & $\begin{array}{c}0.00^{*} \\
(0.080)\end{array}$ & $\begin{array}{c}0.02^{*} \\
(0.088)\end{array}$ & $\begin{array}{c}0.03^{* * *} \\
(0.006)\end{array}$ \\
\hline $\mathrm{Age}^{2}$ & $\begin{array}{r}0.00 \\
(0.326)\end{array}$ & $\begin{array}{r}-0.00 \\
(0.425)\end{array}$ & $\begin{array}{r}-0.00 \\
(0.646)\end{array}$ & $\begin{array}{r}-0.00 \\
(0.407)\end{array}$ \\
\hline Some College & $\begin{array}{r}0.03 \\
(0.195)\end{array}$ & $\begin{array}{r}-0.02 \\
(0.242)\end{array}$ & $\begin{array}{r}-0.21 \\
(0.130)\end{array}$ & $\begin{array}{r}-0.19 \\
(0.162)\end{array}$ \\
\hline BA or more & $\begin{array}{r}0.00 \\
(0.997)\end{array}$ & $\begin{array}{l}-0.07^{* *} \\
(0.038)\end{array}$ & $\begin{array}{r}-0.08 \\
(0.728)\end{array}$ & $\begin{array}{r}-0.06 \\
(0.798)\end{array}$ \\
\hline Cognitive Skill & $\begin{array}{r}0.08 \\
(0.140)\end{array}$ & $\begin{array}{l}-0.15^{* * *} \\
(0.006)\end{array}$ & $\begin{array}{l}-0.92^{* *} \\
(0.016)\end{array}$ & $\begin{array}{l}-0.80^{* *} \\
(0.032)\end{array}$ \\
\hline Extraversion & $\begin{array}{r}-0.07 \\
(0.374)\end{array}$ & $\begin{array}{r}-0.01 \\
(0.925)\end{array}$ & $\begin{array}{r}0.13 \\
(0.821)\end{array}$ & $\begin{array}{c}1.06^{*} \\
(0.065)\end{array}$ \\
\hline Neuroticism & $\begin{array}{l}-0.20^{\text {*** }} \\
(0.003)\end{array}$ & $\begin{array}{r}-0.11 \\
(0.123)\end{array}$ & $\begin{array}{l}1.26^{* * *} \\
(0.007)\end{array}$ & $\begin{array}{l}1.33^{* * *} \\
(0.004)\end{array}$ \\
\hline Agreeableness & $\begin{array}{r}-0.08 \\
(0.186)\end{array}$ & $\begin{array}{r}0.01 \\
(0.895)\end{array}$ & $\begin{array}{r}0.43 \\
(0.341)\end{array}$ & $\begin{array}{r}0.59 \\
(0.179)\end{array}$ \\
\hline Inhibitive Side of Consc. & $\begin{array}{r}-0.09 \\
(0.188)\end{array}$ & $\begin{array}{r}-0.12 \\
(0.116)\end{array}$ & $\begin{array}{r}0.48 \\
(0.341)\end{array}$ & $\begin{array}{r}0.59 \\
(0.230)\end{array}$ \\
\hline Proactive Side of Consc. & $\begin{array}{r}0.00 \\
(0.941)\end{array}$ & $\begin{array}{r}-0.01 \\
(0.876)\end{array}$ & $\begin{array}{r}0.22 \\
(0.635)\end{array}$ & $\begin{array}{r}-0.16 \\
(0.726)\end{array}$ \\
\hline Constant & $\begin{array}{c}0.88^{* * *} \\
(0.000)\end{array}$ & $\begin{array}{c}0.81^{* * * *} \\
(0.000)\end{array}$ & $\begin{array}{r}-0.23 \\
(0.749)\end{array}$ & $\begin{array}{l}-1.22^{*} \\
(0.080)\end{array}$ \\
\hline r2 & 0.059 & 0.044 & 0.049 & 0.066 \\
\hline $\mathrm{N}$ & 861 & 861 & 861 & 861 \\
\hline
\end{tabular}


Table 4: Determinants of the difference between attitude to risk and ambiguity. The dependent variable is the difference between the numbers of lotteries accepted in all risk choices and those accepted in all ambiguity choices.

\begin{tabular}{|c|c|c|c|}
\hline & $\begin{array}{r}(1) \\
\text { beta/p }\end{array}$ & $\begin{array}{r}(2) \\
\text { beta/p }\end{array}$ & $\begin{array}{r}(3) \\
\text { beta/p }\end{array}$ \\
\hline \multirow[t]{2}{*}{ Female } & 0.01 & 0.03 & 0.03 \\
\hline & $(0.756)$ & $(0.361)$ & $(0.371)$ \\
\hline \multirow[t]{2}{*}{ African-American } & 0.03 & $0.08 * *$ & $0.08^{* *}$ \\
\hline & $(0.306)$ & $(0.026)$ & $(0.034)$ \\
\hline \multirow[t]{2}{*}{ Native American } & 0.00 & 0.01 & 0.02 \\
\hline & $(0.888)$ & $(0.670)$ & $(0.635)$ \\
\hline \multirow[t]{2}{*}{ Asian } & 0.05 & -0.01 & -0.01 \\
\hline & $(0.115)$ & $(0.795)$ & $(0.780)$ \\
\hline \multirow[t]{2}{*}{ Separated } & 0.01 & -0.03 & -0.03 \\
\hline & $(0.851)$ & $(0.382)$ & $(0.375)$ \\
\hline \multirow[t]{2}{*}{ Divorced } & 0.04 & $0.06^{*}$ & $0.07^{*}$ \\
\hline & $(0.187)$ & $(0.081)$ & $(0.075)$ \\
\hline \multirow[t]{2}{*}{ Never Married } & 0.01 & 0.01 & 0.01 \\
\hline & $(0.817)$ & $(0.867)$ & $(0.793)$ \\
\hline \multirow[t]{2}{*}{ Age } & -0.03 & -0.08 & -0.08 \\
\hline & $(0.652)$ & $(0.246)$ & $(0.268)$ \\
\hline \multirow[t]{2}{*}{$\mathrm{Age}^{2}$} & 0.02 & 0.07 & 0.07 \\
\hline & $(0.750)$ & $(0.306)$ & $(0.315)$ \\
\hline \multirow[t]{2}{*}{ Some College } & 0.03 & 0.03 & 0.04 \\
\hline & $(0.406)$ & $(0.371)$ & $(0.361)$ \\
\hline \multirow[t]{2}{*}{ BA or more } & 0.02 & 0.03 & 0.03 \\
\hline & $(0.472)$ & $(0.437)$ & $(0.456)$ \\
\hline \multirow[t]{2}{*}{ Cognitive Skill } & & 0.03 & 0.04 \\
\hline & & $(0.384)$ & $(0.357)$ \\
\hline \multirow[t]{2}{*}{ Extraversion } & & $-0.08 * *$ & $-0.08^{* *}$ \\
\hline & & $(0.039)$ & $(0.027)$ \\
\hline \multirow[t]{2}{*}{ Neuroticism } & & -0.03 & -0.02 \\
\hline & & $(0.431)$ & $(0.620)$ \\
\hline \multirow[t]{2}{*}{ Agreeableness } & & -0.03 & -0.04 \\
\hline & & $(0.475)$ & $(0.324)$ \\
\hline \multirow[t]{2}{*}{ Conscientiousness } & & -0.02 & \\
\hline & & $(0.596)$ & \\
\hline \multirow[t]{2}{*}{ Inhibitive Side of Consc. } & & & 0.01 \\
\hline & & & $(0.798)$ \\
\hline \multirow[t]{2}{*}{ Proactive Side of Consc. } & & & 0.01 \\
\hline & & & $(0.740)$ \\
\hline $\mathrm{r} 2$ & 0.012 & 0.023 & 0.023 \\
\hline $\mathrm{N}$ & 1068 & 861 & 861 \\
\hline
\end{tabular}


Table 5: Determinants of delay acceptance. The dependent variable is Delay acceptance (defined as the fraction of times the subjects chooses the later payment).

\begin{tabular}{|c|c|c|c|}
\hline & $\begin{array}{r}(1) \\
b / p\end{array}$ & $\begin{array}{r}(2) \\
b / p\end{array}$ & $\begin{array}{r}(3) \\
b / p\end{array}$ \\
\hline \multirow[t]{2}{*}{ Female } & 0.01 & -0.02 & -0.02 \\
\hline & $(0.812)$ & $(0.464)$ & $(0.444)$ \\
\hline \multirow[t]{2}{*}{ African-American } & $-0.14^{* * *}$ & $-0.10^{* * *}$ & $-0.11^{* * *}$ \\
\hline & $(0.000)$ & $(0.001)$ & $(0.000)$ \\
\hline \multirow[t]{2}{*}{ Native American } & 0.06 & 0.03 & 0.04 \\
\hline & $(0.302)$ & $(0.611)$ & $(0.524)$ \\
\hline \multirow[t]{2}{*}{ Asian } & 0.01 & 0.03 & 0.02 \\
\hline & $(0.953)$ & $(0.799)$ & $(0.861)$ \\
\hline \multirow[t]{2}{*}{ Separated } & -0.05 & -0.07 & -0.06 \\
\hline & $(0.263)$ & $(0.203)$ & $(0.276)$ \\
\hline \multirow[t]{2}{*}{ Divorced } & 0.03 & 0.03 & 0.03 \\
\hline & $(0.235)$ & $(0.266)$ & $(0.245)$ \\
\hline \multirow[t]{2}{*}{ Never Married } & 0.02 & 0.02 & 0.02 \\
\hline & $(0.386)$ & $(0.383)$ & $(0.365)$ \\
\hline \multirow[t]{2}{*}{ Age } & 0.00 & 0.00 & 0.00 \\
\hline & $(0.274)$ & $(0.336)$ & $(0.343)$ \\
\hline \multirow[t]{2}{*}{$\operatorname{Age}^{2}$} & 0.00 & 0.00 & 0.00 \\
\hline & $(0.175)$ & $(0.110)$ & $(0.103)$ \\
\hline \multirow[t]{2}{*}{ Some College } & $0.06^{* * *}$ & 0.03 & 0.03 \\
\hline & $(0.001)$ & $(0.154)$ & $(0.167)$ \\
\hline \multirow[t]{2}{*}{$\mathrm{BA}$ or more } & $0.17^{* * *}$ & $0.11^{* * *}$ & $0.10^{* * *}$ \\
\hline & $(0.000)$ & $(0.006)$ & $(0.007)$ \\
\hline \multirow[t]{2}{*}{ Cognitive Skill } & & $0.34^{* * *}$ & $0.34^{* * *}$ \\
\hline & & $(0.000)$ & $(0.000)$ \\
\hline \multirow[t]{2}{*}{ Extraversion } & & -0.02 & 0.00 \\
\hline & & $(0.870)$ & $(0.971)$ \\
\hline \multirow[t]{2}{*}{ Neuroticism } & & 0.05 & 0.02 \\
\hline & & $(0.499)$ & $(0.753)$ \\
\hline \multirow[t]{2}{*}{ Agreeableness } & & 0.09 & 0.08 \\
\hline & & $(0.180)$ & $(0.282)$ \\
\hline \multirow[t]{2}{*}{ Conscientiousness } & & 0.04 & \\
\hline & & $(0.579)$ & \\
\hline \multirow[t]{2}{*}{ Inhibitive Side of Consc. } & & & $0.13^{*}$ \\
\hline & & & $(0.098)$ \\
\hline \multirow[t]{2}{*}{ Proactive Side of Consc. } & & & -0.07 \\
\hline & & & $(0.353)$ \\
\hline \multirow[t]{2}{*}{ Constant } & $0.53^{* * *}$ & $0.22^{* *}$ & $0.21^{*}$ \\
\hline & $(0.000)$ & $(0.041)$ & $(0.065)$ \\
\hline $\mathrm{r} 2$ & 0.080 & 0.115 & 0.118 \\
\hline $\mathrm{N}$ & 1068 & 861 & 861 \\
\hline
\end{tabular}


Table 6: Determinants of delay acceptance when early payments are immediate and delayed. The first two columns report results for Delay Acceptance (DAcc) Imm. (respectively DAcc Later) (defined as the fraction of times the subject chose a later payment in a choice where the early payment was made immediately (at a later date, respectively)). The last two report results for the estimated $\beta$ and $\delta$.

\begin{tabular}{|c|c|c|c|c|}
\hline & $\begin{array}{r}\text { DAcc Imm. } \\
\mathrm{b} / \mathrm{p}\end{array}$ & $\begin{array}{r}\text { DA Later } \\
\mathrm{b} / \mathrm{p}\end{array}$ & $\begin{array}{r}\beta \\
b / p\end{array}$ & $\begin{array}{r}\delta \\
\mathrm{b} / \mathrm{p}\end{array}$ \\
\hline \multirow{2}{*}{ Female } & -0.00 & -0.05 & 0.01 & -0.00 \\
\hline & $(0.915)$ & $(0.234)$ & $(0.440)$ & $(0.350)$ \\
\hline \multirow{2}{*}{ African-American } & $-0.10 * * *$ & $-0.13^{* * *}$ & $-0.04^{* * *}$ & $-0.00 * * *$ \\
\hline & $(0.002)$ & $(0.001)$ & $(0.007)$ & $(0.001)$ \\
\hline \multirow[t]{2}{*}{ Native American } & 0.06 & 0.02 & 0.02 & 0.00 \\
\hline & $(0.380)$ & $(0.750)$ & $(0.451)$ & $(0.458)$ \\
\hline \multirow[t]{2}{*}{ Asian } & 0.03 & 0.02 & 0.01 & 0.00 \\
\hline & $(0.852)$ & $(0.895)$ & $(0.891)$ & $(0.891)$ \\
\hline \multirow[t]{2}{*}{ Separated } & -0.03 & -0.08 & -0.00 & -0.00 \\
\hline & $(0.524)$ & $(0.201)$ & $(0.995)$ & $(0.265)$ \\
\hline \multirow[t]{2}{*}{ Divorced } & 0.04 & 0.02 & 0.02 & 0.00 \\
\hline & $(0.119)$ & $(0.539)$ & $(0.109)$ & $(0.455)$ \\
\hline \multirow[t]{2}{*}{ Never Married } & 0.02 & 0.02 & 0.01 & 0.00 \\
\hline & $(0.404)$ & $(0.421)$ & $(0.565)$ & $(0.405)$ \\
\hline \multirow[t]{2}{*}{ Age } & 0.00 & 0.00 & -0.00 & 0.00 \\
\hline & $(0.812)$ & $(0.167)$ & $(0.888)$ & $(0.318)$ \\
\hline \multirow[t]{2}{*}{$\mathrm{Age}^{2}$} & $0.00^{*}$ & 0.00 & 0.00 & 0.00 \\
\hline & $(0.100)$ & $(0.186)$ & $(0.136)$ & $(0.122)$ \\
\hline \multirow[t]{2}{*}{ Some College } & 0.02 & 0.04 & 0.01 & $0.00^{*}$ \\
\hline & $(0.319)$ & $(0.143)$ & $(0.223)$ & $(0.073)$ \\
\hline \multirow[t]{2}{*}{$\mathrm{BA}$ or more } & $0.10^{* *}$ & $0.11^{* *}$ & $0.04^{* *}$ & $0.00^{* *}$ \\
\hline & $(0.015)$ & $(0.014)$ & $(0.022)$ & $(0.012)$ \\
\hline \multirow[t]{2}{*}{ Cognitive Skill } & $0.32 * * *$ & $0.36^{* * *}$ & $0.12^{* * *}$ & $0.01^{* * *}$ \\
\hline & $(0.000)$ & $(0.000)$ & $(0.000)$ & $(0.000)$ \\
\hline \multirow[t]{2}{*}{ Extraversion } & 0.06 & -0.06 & 0.03 & 0.00 \\
\hline & $(0.508)$ & $(0.615)$ & $(0.410)$ & $(0.943)$ \\
\hline \multirow[t]{2}{*}{ Neuroticism } & 0.06 & -0.01 & 0.05 & -0.00 \\
\hline & $(0.416)$ & $(0.868)$ & $(0.132)$ & $(0.908)$ \\
\hline \multirow[t]{2}{*}{ Agreeableness } & 0.08 & 0.07 & 0.05 & 0.00 \\
\hline & $(0.248)$ & $(0.416)$ & $(0.133)$ & $(0.901)$ \\
\hline \multirow[t]{2}{*}{ Inhibitive Side of Consc. } & $0.14^{*}$ & 0.13 & 0.05 & 0.00 \\
\hline & $(0.088)$ & $(0.188)$ & $(0.128)$ & $(0.225)$ \\
\hline \multirow[t]{2}{*}{ Proactive Side of Consc. } & -0.06 & -0.07 & -0.03 & -0.00 \\
\hline & $(0.398)$ & $(0.404)$ & $(0.378)$ & $(0.450)$ \\
\hline \multirow[t]{2}{*}{ Constant } & $0.29 * *$ & 0.13 & $0.72^{* * *}$ & $0.98 * * *$ \\
\hline & $(0.011)$ & $(0.350)$ & $(0.000)$ & $(0.000)$ \\
\hline $\mathrm{r} 2$ & 0.095 & 0.107 & 0.088 & 0.101 \\
\hline $\mathrm{N}$ & 861 & 861 & 807 & 807 \\
\hline
\end{tabular}


Table 7: Determinants of beliefs about others' behavior in the sequential prisoner's dilemma game. The dependent variable in the first column is the answer to the question "What percent of the participants do you think will send their 5 dollars?"; in the second and third column, the answer to the questions "If Person 1 does send 0 (5) dollars, what is the average amount that participants in this room will send back?"

\begin{tabular}{|c|c|c|c|}
\hline & $\begin{array}{r}\text { Percent Send } \\
\mathrm{b} / \mathrm{p}\end{array}$ & $\begin{array}{r}\text { Guess } 0 \\
\mathrm{~b} / \mathrm{p}\end{array}$ & $\begin{array}{r}\text { Guess } 5 \\
\mathrm{~b} / \mathrm{p}\end{array}$ \\
\hline \multirow{2}{*}{ Female } & -0.41 & 0.14 & -0.03 \\
\hline & $(0.902)$ & $(0.441)$ & $(0.849)$ \\
\hline \multirow[t]{2}{*}{ African-American } & -1.10 & 0.03 & -0.07 \\
\hline & $(0.736)$ & $(0.853)$ & $(0.699)$ \\
\hline \multirow{2}{*}{ Native American } & 8.78 & 0.09 & 0.36 \\
\hline & $(0.179)$ & $(0.807)$ & $(0.311)$ \\
\hline \multirow[t]{2}{*}{ Asian } & -17.66 & -0.72 & $-2.21^{* * *}$ \\
\hline & (0.193) & $(0.319)$ & (0.002) \\
\hline \multirow[t]{2}{*}{ Separated } & -7.45 & 0.27 & 0.11 \\
\hline & $(0.174)$ & $(0.349)$ & $(0.704)$ \\
\hline \multirow[t]{2}{*}{ Divorced } & -2.35 & 0.12 & -0.18 \\
\hline & $(0.412)$ & $(0.426)$ & $(0.240)$ \\
\hline \multirow[t]{2}{*}{ Never Married } & $7.99^{* * *}$ & 0.17 & $0.29^{* *}$ \\
\hline & (0.003) & $(0.215)$ & $(0.043)$ \\
\hline \multirow[t]{2}{*}{ Age } & 0.18 & $0.02^{* *}$ & 0.01 \\
\hline & $(0.360)$ & $(0.045)$ & $(0.460)$ \\
\hline \multirow[t]{2}{*}{$\mathrm{Age}^{2}$} & -0.01 & -0.00 & -0.00 \\
\hline & $(0.462)$ & $(0.859)$ & $(0.528)$ \\
\hline \multirow[t]{2}{*}{ Some College } & 0.77 & 0.07 & 0.11 \\
\hline & $(0.737)$ & $(0.545)$ & $(0.351)$ \\
\hline \multirow[t]{2}{*}{ BA or more } & -1.61 & $-0.46^{* *}$ & 0.00 \\
\hline & $(0.681)$ & $(0.030)$ & $(0.982)$ \\
\hline \multirow[t]{2}{*}{ Cognitive Skill } & $20.45^{* * *}$ & $-1.64^{* * *}$ & 0.52 \\
\hline & (0.001) & $(0.000)$ & $(0.130)$ \\
\hline \multirow[t]{2}{*}{ Extraversion } & 7.21 & 0.56 & 0.75 \\
\hline & $(0.450)$ & $(0.269)$ & $(0.142)$ \\
\hline \multirow[t]{2}{*}{ Neuroticism } & -10.42 & $0.78^{*}$ & $0.79^{*}$ \\
\hline & $(0.170)$ & $(0.055)$ & $(0.052)$ \\
\hline \multirow[t]{2}{*}{ Agreeableness } & $18.16^{* *}$ & 0.25 & $0.85^{* *}$ \\
\hline & $(0.013)$ & $(0.523)$ & $(0.030)$ \\
\hline \multirow[t]{2}{*}{ Inhibitive Side of Consc. } & 3.40 & 0.49 & 0.46 \\
\hline & $(0.677)$ & $(0.258)$ & $(0.290)$ \\
\hline \multirow[t]{2}{*}{ Proactive Side of Consc. } & -10.39 & -0.05 & -0.33 \\
\hline & $(0.167)$ & $(0.893)$ & $(0.411)$ \\
\hline \multirow[t]{2}{*}{ Delay Acceptance } & $7.72^{* *}$ & 0.27 & 0.15 \\
\hline & $(0.028)$ & $(0.147)$ & $(0.438)$ \\
\hline \multirow[t]{2}{*}{ Risk Acceptance } & $9.85^{* *}$ & 0.04 & $0.60^{* *}$ \\
\hline & $(0.028)$ & $(0.876)$ & $(0.012)$ \\
\hline \multirow{2}{*}{ Constant } & 15.96 & $1.12^{*}$ & 1.00 \\
\hline & $(0.191)$ & $(0.085)$ & $(0.129)$ \\
\hline r2 & 0.072 & 0.081 & 0.046 \\
\hline $\mathrm{N}$ & 859 & 859 & 859 \\
\hline
\end{tabular}


Table 8: Determinants of the decision to send $\mathbf{5}$ dollars as first mover. Logit regressions of the variable equal to one if the subject sent 5 dollars. Marginal effects at the mean of the dependent variables.

\begin{tabular}{|c|c|c|c|c|c|}
\hline & (1) & (2) & (3) & (4) & (5) \\
\hline & $\mathrm{b} / \mathrm{p}$ & $\mathrm{b} / \mathrm{p}$ & $\mathrm{b} / \mathrm{p}$ & $\mathrm{b} / \mathrm{p}$ & $\mathrm{b} / \mathrm{p}$ \\
\hline \multirow[t]{2}{*}{ Female } & -0.01 & -0.08 & -0.01 & -0.08 & -0.07 \\
\hline & $(0.808)$ & $(0.163)$ & $(0.841)$ & (0.187) & $(0.194)$ \\
\hline \multirow[t]{2}{*}{ African-American } & $-0.09^{*}$ & -0.05 & -0.05 & -0.03 & -0.03 \\
\hline & $(0.050)$ & $(0.332)$ & $(0.234)$ & $(0.514)$ & $(0.605)$ \\
\hline \multirow{2}{*}{ Native American } & -0.02 & 0.04 & -0.06 & 0.02 & 0.01 \\
\hline & $(0.826)$ & $(0.697)$ & $(0.566)$ & (0.879) & $(0.963)$ \\
\hline \multirow[t]{2}{*}{ Asian } & -0.04 & 0.00 & -0.07 & -0.02 & -0.02 \\
\hline & $(0.807)$ & $(0.992)$ & (0.679) & (0.908) & $(0.916)$ \\
\hline \multirow[t]{2}{*}{ Separated } & -0.12 & -0.02 & -0.10 & -0.00 & -0.01 \\
\hline & $(0.134)$ & $(0.855)$ & $(0.200)$ & (0.998) & $(0.940)$ \\
\hline \multirow[t]{2}{*}{ Divorced } & -0.04 & -0.02 & -0.05 & -0.04 & -0.03 \\
\hline & $(0.373)$ & $(0.610)$ & $(0.225)$ & $(0.465)$ & $(0.477)$ \\
\hline \multirow[t]{2}{*}{ Never Married } & -0.03 & 0.00 & -0.04 & 0.00 & -0.00 \\
\hline & $(0.390)$ & $(0.953)$ & $(0.347)$ & $(0.962)$ & $(0.992)$ \\
\hline \multirow[t]{2}{*}{ Age } & 0.00 & 0.00 & 0.00 & 0.00 & 0.00 \\
\hline & $(0.105)$ & (0.394) & $(0.144)$ & $(0.401)$ & $(0.420)$ \\
\hline \multirow[t]{2}{*}{$\mathrm{Age}^{2}$} & 0.00 & 0.00 & 0.00 & 0.00 & 0.00 \\
\hline & $(0.973)$ & $(0.270)$ & $(0.996)$ & (0.308) & $(0.317)$ \\
\hline \multirow[t]{2}{*}{ Some College } & $0.09^{* * *}$ & $0.07^{* *}$ & $0.08^{* * *}$ & $0.07^{*}$ & $0.07^{*}$ \\
\hline & $(0.002)$ & $(0.045)$ & $(0.006)$ & $(0.058)$ & $(0.067)$ \\
\hline \multirow[t]{2}{*}{ BA or more } & $0.10^{* *}$ & 0.04 & 0.08 & 0.03 & 0.03 \\
\hline & $(0.043)$ & $(0.551)$ & $(0.116)$ & $(0.596)$ & $(0.634)$ \\
\hline \multirow[t]{2}{*}{ Cognitive Skill } & & $0.18^{*}$ & & 0.15 & 0.14 \\
\hline & & $(0.067)$ & & (0.144) & $(0.153)$ \\
\hline \multirow[t]{2}{*}{ Extraversion } & & 0.00 & & 0.00 & -0.01 \\
\hline & & $(0.996)$ & & (0.990) & $(0.973)$ \\
\hline \multirow{2}{*}{ Neuroticism } & & 0.15 & & 0.17 & 0.14 \\
\hline & & (0.194) & & $(0.142)$ & $(0.252)$ \\
\hline \multirow[t]{2}{*}{ Agreeableness } & & $0.50^{* * *}$ & & $0.50^{* * *}$ & $0.51^{* * *}$ \\
\hline & & $(0.000)$ & & (0.000) & $(0.000)$ \\
\hline \multirow[t]{2}{*}{ Conscientiousness } & & $-0.26^{* *}$ & & $-0.25 *$ & \\
\hline & & $(0.044)$ & & $(0.051)$ & \\
\hline Inhibitive Side of Consc. & & & & & $\begin{array}{r}-0.16 \\
(0.232)\end{array}$ \\
\hline Proactive Side of Consc. & & & & & $\begin{array}{r}-0.20 \\
(0.101)\end{array}$ \\
\hline \multirow[t]{2}{*}{ Delay Acceptance } & & & $0.19 * * *$ & $0.11^{* *}$ & $0.11 *$ \\
\hline & & & $(0.000)$ & $(0.049)$ & $(0.050)$ \\
\hline Risk Acceptance & & & $0.22^{* * *}$ & $0.19^{* * *}$ & $0.19^{* * *}$ \\
\hline $\mathrm{N}$ & 1068 & 861 & 1068 & 861 & 861 \\
\hline
\end{tabular}


Table 9: Determinants of the amount sent back by second mover, after a transfer of $\mathbf{0}$ dollars. The dependent variable is the amount sent by the subject as second mover after a transfer of 0 dollars by the first.

\begin{tabular}{|c|c|c|c|c|c|}
\hline & (1) & $(2)$ & $(3)$ & (4) & $(5)$ \\
\hline & $\mathrm{b} / \mathrm{p}$ & $\mathrm{b} / \mathrm{p}$ & $\mathrm{b} / \mathrm{p}$ & $\mathrm{b} / \mathrm{p}$ & $\mathrm{b} / \mathrm{p}$ \\
\hline \multirow[t]{2}{*}{ Female } & 0.16 & 0.00 & 0.18 & 0.01 & 0.01 \\
\hline & $(0.445)$ & $(0.989)$ & $(0.384)$ & $(0.974)$ & $(0.951)$ \\
\hline \multirow[t]{2}{*}{ African-American } & 0.02 & -0.21 & 0.03 & -0.20 & -0.15 \\
\hline & $(0.930)$ & $(0.320)$ & $(0.879)$ & $(0.349)$ & $(0.479)$ \\
\hline \multirow{2}{*}{ Native American } & $0.70^{*}$ & 0.40 & 0.60 & 0.31 & 0.27 \\
\hline & $(0.070)$ & $(0.351)$ & $(0.117)$ & $(0.467)$ & $(0.538)$ \\
\hline \multirow[t]{2}{*}{ Asian } & 0.04 & 0.01 & -0.07 & -0.08 & -0.04 \\
\hline & $(0.951)$ & $(0.992)$ & $(0.921)$ & $(0.925)$ & $(0.967)$ \\
\hline \multirow[t]{2}{*}{ Separated } & 0.10 & 0.30 & 0.13 & 0.33 & 0.29 \\
\hline & $(0.750)$ & $(0.405)$ & $(0.675)$ & $(0.358)$ & $(0.430)$ \\
\hline \multirow[t]{2}{*}{ Divorced } & 0.15 & 0.26 & 0.12 & 0.24 & 0.23 \\
\hline & $(0.403)$ & $(0.171)$ & $(0.496)$ & $(0.215)$ & $(0.225)$ \\
\hline \multirow[t]{2}{*}{ Never Married } & -0.07 & -0.10 & -0.06 & -0.08 & -0.09 \\
\hline & $(0.667)$ & $(0.579)$ & $(0.683)$ & $(0.631)$ & $(0.601)$ \\
\hline \multirow[t]{2}{*}{ Age } & $0.03^{* *}$ & 0.02 & $0.03^{* *}$ & 0.02 & 0.02 \\
\hline & $(0.015)$ & $(0.233)$ & $(0.017)$ & $(0.204)$ & $(0.208)$ \\
\hline \multirow[t]{2}{*}{$\mathrm{Age}^{2}$} & -0.00 & -0.00 & -0.00 & -0.00 & -0.00 \\
\hline & $(0.740)$ & $(0.948)$ & $(0.860)$ & $(0.973)$ & $(0.955)$ \\
\hline \multirow[t]{2}{*}{ Some College } & -0.16 & 0.00 & -0.15 & 0.01 & 0.01 \\
\hline & $(0.218)$ & $(0.984)$ & $(0.259)$ & $(0.957)$ & $(0.958)$ \\
\hline \multirow[t]{2}{*}{ BA or more } & $-0.78^{* * *}$ & $-0.52^{* *}$ & $-0.71 * * *$ & $-0.46^{*}$ & $-0.46^{*}$ \\
\hline & $(0.001)$ & $(0.047)$ & $(0.003)$ & $(0.076)$ & $(0.078)$ \\
\hline \multirow[t]{2}{*}{ Cognitive Skill } & & $-1.55^{* * *}$ & & $-1.46^{* * *}$ & $-1.47 * * *$ \\
\hline & & $(0.000)$ & & $(0.001)$ & $(0.000)$ \\
\hline \multirow[t]{2}{*}{ Extraversion } & & 0.69 & & 0.71 & 0.63 \\
\hline & & $(0.281)$ & & $(0.260)$ & $(0.317)$ \\
\hline \multirow[t]{2}{*}{ Neuroticism } & & $0.83^{*}$ & & $0.99 * *$ & $1.04^{* *}$ \\
\hline & & $(0.085)$ & & $(0.041)$ & $(0.040)$ \\
\hline \multirow[t]{2}{*}{ Agreeableness } & & $1.37 * * *$ & & $1.44^{* * *}$ & $1.54^{* * *}$ \\
\hline & & $(0.004)$ & & $(0.002)$ & $(0.002)$ \\
\hline \multirow[t]{2}{*}{ Conscientiousness } & & -0.53 & & -0.47 & \\
\hline & & $(0.306)$ & & $(0.366)$ & \\
\hline \multirow[t]{2}{*}{ Inhibitive Side of Consc. } & & & & & -0.73 \\
\hline & & & & & $(0.177)$ \\
\hline \multirow[t]{2}{*}{ Proactive Side of Consc. } & & & & & 0.00 \\
\hline & & & & & $(0.992)$ \\
\hline \multirow[t]{2}{*}{ Delay Acceptance } & & & -0.10 & -0.18 & -0.17 \\
\hline & & & $(0.645)$ & $(0.435)$ & $(0.470)$ \\
\hline \multirow[t]{2}{*}{ Risk Acceptance } & & & $0.99^{* * *}$ & $0.94^{* * *}$ & $0.92^{* * *}$ \\
\hline & & & $(0.000)$ & $(0.002)$ & $(0.002)$ \\
\hline \multirow[t]{2}{*}{ Constant } & $1.61^{* * *}$ & $1.38^{*}$ & $1.03^{* * *}$ & 0.65 & 0.82 \\
\hline & $(0.000)$ & $(0.056)$ & $(0.000)$ & $(0.392)$ & $(0.311)$ \\
\hline r2 & 0.035 & 0.067 & 0.047 & 0.078 & 0.079 \\
\hline $\mathrm{N}$ & 1068 & 861 & 1068 & 861 & 861 \\
\hline
\end{tabular}


Table 10: Determinants of the amount sent back by second mover, after a transfer of $\mathbf{5}$ dollars. The dependent variable is the amount sent by the subject as second mover after a transfer of 5 dollars by the first.

\begin{tabular}{|c|c|c|c|c|c|}
\hline & (1) & $(2)$ & $(3)$ & (4) & $(5)$ \\
\hline & $\mathrm{b} / \mathrm{p}$ & $\mathrm{b} / \mathrm{p}$ & $\mathrm{b} / \mathrm{p}$ & $\mathrm{b} / \mathrm{p}$ & $\mathrm{b} / \mathrm{p}$ \\
\hline \multirow[t]{2}{*}{ Female } & -0.22 & $-0.36^{*}$ & -0.21 & $-0.34^{*}$ & -0.34 \\
\hline & $(0.257)$ & $(0.083)$ & $(0.271)$ & $(0.098)$ & $(0.101)$ \\
\hline \multirow[t]{2}{*}{ African-American } & -0.23 & -0.06 & -0.11 & 0.02 & 0.02 \\
\hline & $(0.171)$ & $(0.763)$ & $(0.498)$ & $(0.924)$ & $(0.925)$ \\
\hline \multirow[t]{2}{*}{ Native American } & -0.30 & -0.51 & -0.40 & -0.61 & -0.63 \\
\hline & $(0.403)$ & $(0.207)$ & $(0.257)$ & $(0.134)$ & $(0.123)$ \\
\hline \multirow[t]{2}{*}{ Asian } & -0.36 & -0.44 & -0.44 & -0.54 & -0.55 \\
\hline & $(0.587)$ & $(0.602)$ & $(0.506)$ & $(0.522)$ & $(0.516)$ \\
\hline \multirow[t]{2}{*}{ Separated } & -0.37 & -0.04 & -0.31 & 0.03 & 0.04 \\
\hline & $(0.205)$ & $(0.913)$ & $(0.282)$ & $(0.925)$ & $(0.901)$ \\
\hline \multirow[t]{2}{*}{ Divorced } & -0.24 & -0.17 & $-0.28 *$ & -0.21 & -0.21 \\
\hline & $(0.145)$ & $(0.351)$ & $(0.086)$ & $(0.242)$ & $(0.245)$ \\
\hline \multirow[t]{2}{*}{ Never Married } & -0.08 & -0.02 & -0.09 & -0.03 & -0.04 \\
\hline & $(0.604)$ & $(0.896)$ & $(0.542)$ & $(0.875)$ & $(0.814)$ \\
\hline \multirow[t]{2}{*}{ Age } & 0.01 & 0.01 & 0.01 & 0.01 & 0.01 \\
\hline & $(0.415)$ & $(0.606)$ & $(0.520)$ & $(0.631)$ & $(0.678)$ \\
\hline \multirow[t]{2}{*}{$\mathrm{Age}^{2}$} & -0.00 & -0.00 & -0.00 & -0.00 & -0.00 \\
\hline & $(0.782)$ & $(0.770)$ & $(0.739)$ & $(0.664)$ & $(0.677)$ \\
\hline \multirow[t]{2}{*}{ Some College } & $0.43^{* * *}$ & $0.25 *$ & $0.39 * * *$ & 0.23 & 0.22 \\
\hline & $(0.000)$ & $(0.082)$ & $(0.001)$ & $(0.103)$ & $(0.121)$ \\
\hline \multirow[t]{2}{*}{ BA or more } & $0.50 * *$ & 0.21 & $0.42^{*}$ & 0.18 & 0.17 \\
\hline & $(0.024)$ & $(0.398)$ & $(0.061)$ & $(0.460)$ & $(0.478)$ \\
\hline \multirow[t]{2}{*}{ Cognitive Skill } & & $1.04^{* * *}$ & & $0.89 * *$ & $0.87 * *$ \\
\hline & & $(0.007)$ & & $(0.023)$ & $(0.026)$ \\
\hline \multirow[t]{2}{*}{ Extraversion } & & -0.07 & & -0.04 & 0.04 \\
\hline & & $(0.908)$ & & $(0.950)$ & $(0.946)$ \\
\hline \multirow[t]{2}{*}{ Neuroticism } & & $0.92^{* *}$ & & $1.01^{* *}$ & $0.78^{*}$ \\
\hline & & $(0.043)$ & & $(0.026)$ & $(0.096)$ \\
\hline \multirow[t]{2}{*}{ Agreeableness } & & $1.57 * * *$ & & $1.56^{* * *}$ & $1.65^{* * *}$ \\
\hline & & $(0.000)$ & & $(0.000)$ & $(0.000)$ \\
\hline \multirow[t]{2}{*}{ Conscientiousness } & & -0.41 & & -0.39 & \\
\hline & & $(0.404)$ & & $(0.429)$ & \\
\hline \multirow[t]{2}{*}{ Inhibitive Side of Consc. } & & & & & -0.16 \\
\hline & & & & & $(0.758)$ \\
\hline \multirow[t]{2}{*}{ Proactive Side of Consc. } & & & & & $-0.81^{*}$ \\
\hline & & & & & $(0.084)$ \\
\hline \multirow[t]{2}{*}{ Delay Acceptance } & & & $0.69 * * *$ & $0.51^{* *}$ & $0.51^{* *}$ \\
\hline & & & $(0.000)$ & $(0.019)$ & $(0.021)$ \\
\hline \multirow[t]{2}{*}{ Risk Acceptance } & & & $0.63^{* *}$ & $0.76^{* * *}$ & $0.75^{* * *}$ \\
\hline & & & $(0.013)$ & $(0.007)$ & $(0.007)$ \\
\hline \multirow[t]{2}{*}{ Constant } & $3.49 * * *$ & $1.75^{* * *}$ & $2.72^{* * *}$ & 1.02 & $1.42^{*}$ \\
\hline & $(0.000)$ & $(0.010)$ & $(0.000)$ & $(0.149)$ & $(0.059)$ \\
\hline r2 & 0.022 & 0.042 & 0.041 & 0.058 & 0.061 \\
\hline $\mathrm{N}$ & 1068 & 861 & 1068 & 861 & 861 \\
\hline
\end{tabular}


Table 11: Determinants of credit score. The dependent variable is the credit score (FICO 98) of the subject.

\begin{tabular}{|c|c|c|c|c|c|}
\hline & (1) & $(2)$ & (3) & (4) & (5) \\
\hline & $\mathrm{b} / \mathrm{p}$ & $\mathrm{b} / \mathrm{p}$ & $\mathrm{b} / \mathrm{p}$ & $\mathrm{b} / \mathrm{p}$ & $\mathrm{b} / \mathrm{p}$ \\
\hline \multirow[t]{2}{*}{ Female } & 1.50 & -1.16 & 1.11 & -1.01 & -1.20 \\
\hline & $(0.871)$ & $(0.909)$ & $(0.904)$ & $(0.920)$ & $(0.905)$ \\
\hline African-American & $\begin{array}{l}-58.37^{* * *} \\
(0.000)\end{array}$ & $\begin{array}{l}-48.39^{* * *} \\
(0.000)\end{array}$ & $\begin{array}{l}-54.09 * * * \\
(0.000)\end{array}$ & $\begin{array}{l}-45.54^{* * *} \\
(0.000)\end{array}$ & $\begin{array}{l}-50.20^{* * *} \\
(0.000)\end{array}$ \\
\hline \multirow[t]{2}{*}{ Native American } & -22.47 & -27.69 & -24.36 & -27.97 & -26.14 \\
\hline & $(0.232)$ & $(0.206)$ & $(0.193)$ & $(0.200)$ & $(0.231)$ \\
\hline \multirow[t]{2}{*}{ Asian } & -36.12 & -38.07 & -35.92 & -38.67 & -45.02 \\
\hline & $(0.242)$ & $(0.332)$ & $(0.241)$ & $(0.322)$ & $(0.249)$ \\
\hline \multirow[t]{2}{*}{ Separated } & -23.29 & -14.30 & -21.82 & -12.12 & -10.23 \\
\hline & $(0.112)$ & $(0.397)$ & $(0.134)$ & $(0.471)$ & $(0.543)$ \\
\hline \multirow[t]{2}{*}{ Divorced } & $-20.90^{* * *}$ & $-23.93^{* * *}$ & $-21.74^{* * *}$ & $-24.35^{* * *}$ & $-23.03^{* * *}$ \\
\hline & $(0.009)$ & $(0.006)$ & $(0.007)$ & $(0.005)$ & $(0.008)$ \\
\hline \multirow[t]{2}{*}{ Never Married } & 5.30 & 9.37 & 4.31 & 8.48 & 9.43 \\
\hline & $(0.466)$ & $(0.251)$ & $(0.551)$ & $(0.296)$ & $(0.245)$ \\
\hline \multirow[t]{2}{*}{ Age } & $1.01^{*}$ & $1.07^{*}$ & $0.91^{*}$ & 0.97 & 0.96 \\
\hline & $(0.062)$ & $(0.079)$ & $(0.091)$ & $(0.108)$ & $(0.112)$ \\
\hline \multirow[t]{2}{*}{$\mathrm{Age}^{2}$} & $0.07^{* * *}$ & $0.08^{* * *}$ & $0.07 * * *$ & $0.07 * * *$ & $0.07^{* * *}$ \\
\hline & $(0.002)$ & $(0.002)$ & $(0.003)$ & $(0.004)$ & $(0.003)$ \\
\hline \multirow[t]{2}{*}{ Some College } & 9.20 & 0.15 & 6.84 & -1.07 & -1.91 \\
\hline & $(0.122)$ & $(0.983)$ & $(0.249)$ & $(0.878)$ & $(0.785)$ \\
\hline \multirow[t]{2}{*}{ BA or more } & $49.77^{* * *}$ & $35.89^{* * *}$ & $43.78^{* * *}$ & $32.21^{* * *}$ & $29.61^{* *}$ \\
\hline & $(0.000)$ & $(0.003)$ & $(0.000)$ & $(0.007)$ & $(0.013)$ \\
\hline \multirow[t]{2}{*}{ Cognitive Skill } & & $45.16^{* *}$ & & $32.32^{*}$ & $34.65^{*}$ \\
\hline & & $(0.020)$ & & $(0.099)$ & $(0.077)$ \\
\hline \multirow[t]{2}{*}{ Extraversion } & & $-77.08^{* * *}$ & & $-75.53^{* *}$ & $-75.47^{* *}$ \\
\hline & & $(0.010)$ & & $(0.011)$ & $(0.010)$ \\
\hline \multirow[t]{2}{*}{ Neuroticism } & & -32.94 & & -32.24 & $-39.75^{*}$ \\
\hline & & $(0.149)$ & & $(0.158)$ & $(0.094)$ \\
\hline \multirow[t]{2}{*}{ Agreeableness } & & 15.38 & & 13.53 & -1.21 \\
\hline & & $(0.491)$ & & $(0.543)$ & $(0.957)$ \\
\hline \multirow[t]{2}{*}{ Conscientiousness } & & $-50.80 * *$ & & $-51.28^{* *}$ & \\
\hline & & $(0.037)$ & & $(0.034)$ & \\
\hline \multirow[t]{2}{*}{ Inhibitive Side of Consc. } & & & & & 39.59 \\
\hline & & & & & $(0.117)$ \\
\hline \multirow[t]{2}{*}{ Proactive Side of Consc. } & & & & & $-57.37 * *$ \\
\hline & & & & & $(0.013)$ \\
\hline \multirow[t]{2}{*}{ Delay Acceptance } & & & $37.87^{* * *}$ & $36.32^{* * *}$ & $35.58^{* * *}$ \\
\hline & & & $(0.000)$ & $(0.001)$ & $(0.001)$ \\
\hline \multirow[t]{2}{*}{ Risk Acceptance } & & & -0.07 & -3.20 & -1.63 \\
\hline & & & $(0.996)$ & $(0.821)$ & $(0.908)$ \\
\hline \multirow[t]{2}{*}{ Constant } & $569.82^{* * *}$ & $618.42^{* * *}$ & $549.80^{* * *}$ & $609.66^{* * *}$ & $598.43^{* * *}$ \\
\hline & $(0.000)$ & $(0.000)$ & $(0.000)$ & $(0.000)$ & $(0.000)$ \\
\hline $\mathrm{r} 2$ & 0.161 & 0.179 & 0.175 & 0.191 & 0.194 \\
\hline $\mathrm{N}$ & 944 & 764 & 944 & 764 & 764 \\
\hline
\end{tabular}


Table 12: Determinants of credit score availability. Logit regressions of the variable equal to one if the credit score of the subject is available. Marginal effects at the mean of the dependent variables.

\begin{tabular}{|c|c|c|c|c|c|}
\hline & (1) & (2) & (3) & (4) & $(5)$ \\
\hline & $\mathrm{b} / \mathrm{p}$ & $\mathrm{b} / \mathrm{p}$ & $\mathrm{b} / \mathrm{p}$ & $\mathrm{b} / \mathrm{p}$ & $\mathrm{b} / \mathrm{p}$ \\
\hline \multirow{2}{*}{ Female } & 0.01 & 0.03 & 0.01 & 0.03 & 0.03 \\
\hline & $(0.767)$ & $(0.296)$ & $(0.774)$ & $(0.277)$ & $(0.270)$ \\
\hline \multirow[t]{2}{*}{ African-American } & $-0.09 * * *$ & -0.04 & $-0.07^{* *}$ & -0.03 & -0.03 \\
\hline & (0.009) & $(0.211)$ & $(0.027)$ & $(0.305)$ & $(0.312)$ \\
\hline \multirow[t]{2}{*}{ Native American } & -0.13 & $-0.20^{*}$ & -0.14 & $-0.21^{*}$ & $-0.21^{*}$ \\
\hline & $(0.126)$ & $(0.063)$ & $(0.102)$ & $(0.055)$ & $(0.054)$ \\
\hline \multirow[t]{2}{*}{ Latino } & 0.06 & 0.06 & $0.06^{*}$ & 0.06 & 0.06 \\
\hline & $(0.104)$ & $(0.190)$ & $(0.080)$ & $(0.144)$ & $(0.137)$ \\
\hline \multirow{2}{*}{ Separated } & -0.08 & -0.02 & -0.07 & -0.01 & -0.01 \\
\hline & $(0.175)$ & $(0.780)$ & $(0.212)$ & $(0.868)$ & $(0.860)$ \\
\hline \multirow[t]{2}{*}{ Divorced } & -0.01 & -0.00 & -0.02 & -0.01 & -0.01 \\
\hline & $(0.680)$ & $(0.879)$ & $(0.584)$ & $(0.801)$ & $(0.813)$ \\
\hline \multirow{2}{*}{ Never Married } & -0.03 & -0.03 & -0.03 & -0.03 & -0.03 \\
\hline & $(0.247)$ & $(0.270)$ & $(0.239)$ & $(0.281)$ & $(0.281)$ \\
\hline \multirow[t]{2}{*}{ Age } & 0.00 & 0.00 & 0.00 & 0.00 & 0.00 \\
\hline & $(0.115)$ & $(0.289)$ & $(0.124)$ & $(0.279)$ & $(0.286)$ \\
\hline \multirow{2}{*}{$\mathrm{Age}^{2}$} & -0.00 & -0.00 & -0.00 & -0.00 & -0.00 \\
\hline & $(0.334)$ & $(0.774)$ & $(0.291)$ & $(0.692)$ & $(0.689)$ \\
\hline \multirow{2}{*}{ Some College } & $0.09^{* * *}$ & $0.06^{* * *}$ & $0.08^{* * *}$ & $0.06^{* * *}$ & $0.06^{* * *}$ \\
\hline & $(0.000)$ & $(0.006)$ & $(0.000)$ & $(0.008)$ & $(0.008)$ \\
\hline \multirow[t]{2}{*}{ BA or more } & $0.05^{* *}$ & 0.03 & 0.04 & 0.03 & 0.03 \\
\hline & $(0.044)$ & $(0.219)$ & $(0.119)$ & $(0.277)$ & $(0.291)$ \\
\hline \multirow[t]{2}{*}{ Cognitive Skill } & & $0.09^{*}$ & & 0.08 & 0.08 \\
\hline & & $(0.096)$ & & $(0.178)$ & $(0.175)$ \\
\hline \multirow[t]{2}{*}{ Extraversion } & & -0.06 & & -0.07 & -0.07 \\
\hline & & $(0.476)$ & & $(0.464)$ & $(0.448)$ \\
\hline \multirow[t]{2}{*}{ Neuroticism } & & 0.09 & & 0.10 & 0.08 \\
\hline & & $(0.181)$ & & $(0.173)$ & $(0.255)$ \\
\hline \multirow[t]{2}{*}{ Agreeableness } & & 0.01 & & 0.00 & 0.00 \\
\hline & & $(0.890)$ & & $(0.958)$ & $(0.973)$ \\
\hline \multirow[t]{2}{*}{ Conscientiousness } & & -0.08 & & -0.08 & \\
\hline & & $(0.274)$ & & $(0.296)$ & \\
\hline Inhibitive Side of Consc. & & & & & $\begin{array}{r}-0.02 \\
(0.781)\end{array}$ \\
\hline Proactive Side of Consc. & & & & & $\begin{array}{r}-0.07 \\
(0.309)\end{array}$ \\
\hline \multirow[t]{2}{*}{ Delay Acceptance } & & & $0.06^{* *}$ & $0.05^{*}$ & $0.05^{*}$ \\
\hline & & & $(0.021)$ & $(0.089)$ & $(0.100)$ \\
\hline \multirow[t]{2}{*}{ Risk Acceptance } & & & 0.04 & 0.04 & 0.04 \\
\hline & & & $(0.228)$ & $(0.321)$ & (0.319) \\
\hline $\mathrm{N}$ & 1068 & 861 & 1068 & 861 & 861 \\
\hline
\end{tabular}


Table 13: Determinants of training exits from the company. Training exits includes all those that did not complete basic training, for any choice-based reason, by either firm or trainee.

\begin{tabular}{|c|c|c|c|c|c|}
\hline & (1) & $(2)$ & $(3)$ & (4) & $(5)$ \\
\hline & $\mathrm{b} / \mathrm{p}$ & $\mathrm{b} / \mathrm{p}$ & $\mathrm{b} / \mathrm{p}$ & $\mathrm{b} / \mathrm{p}$ & $\mathrm{b} / \mathrm{p}$ \\
\hline \multirow[t]{2}{*}{ Female } & 1.38 & 1.29 & 1.39 & 1.28 & 1.28 \\
\hline & $(0.234)$ & $(0.421)$ & $(0.225)$ & $(0.434)$ & $(0.429)$ \\
\hline \multirow[t]{2}{*}{ African-American } & $3.33^{* * *}$ & $2.91^{* * *}$ & $3.20 * * *$ & $2.84^{* * *}$ & $2.66^{* * *}$ \\
\hline & $(0.000)$ & $(0.000)$ & $(0.000)$ & $(0.000)$ & $(0.000)$ \\
\hline \multirow[t]{2}{*}{ Native American } & 0.95 & 0.93 & 0.97 & 0.96 & 1.09 \\
\hline & $(0.927)$ & $(0.922)$ & $(0.960)$ & $(0.953)$ & $(0.909)$ \\
\hline \multirow[t]{2}{*}{ Asian } & $3.74^{*}$ & $7.19^{* *}$ & $3.91^{*}$ & $7.41^{* *}$ & $6.66^{* *}$ \\
\hline & $(0.077)$ & $(0.012)$ & $(0.067)$ & $(0.011)$ & $(0.015)$ \\
\hline \multirow[t]{2}{*}{ Latino } & 1.26 & 1.81 & 1.25 & 1.79 & 1.80 \\
\hline & $(0.750)$ & $(0.425)$ & $(0.761)$ & $(0.433)$ & $(0.427)$ \\
\hline \multirow[t]{2}{*}{ Separated } & 1.11 & 0.81 & 1.10 & 0.78 & 0.80 \\
\hline & $(0.806)$ & $(0.731)$ & $(0.830)$ & $(0.690)$ & $(0.720)$ \\
\hline \multirow[t]{2}{*}{ Divorced } & 1.10 & 0.99 & 1.11 & 1.00 & 1.01 \\
\hline & $(0.718)$ & $(0.961)$ & $(0.681)$ & $(0.994)$ & $(0.977)$ \\
\hline \multirow[t]{2}{*}{ Never Married } & $1.57^{*}$ & 1.40 & $1.57^{*}$ & 1.38 & 1.41 \\
\hline & $(0.066)$ & $(0.227)$ & $(0.066)$ & $(0.250)$ & $(0.219)$ \\
\hline \multirow[t]{2}{*}{ Age } & $1.11^{*}$ & 1.06 & 1.11 & 1.06 & 1.07 \\
\hline & $(0.098)$ & $(0.334)$ & $(0.105)$ & $(0.370)$ & $(0.302)$ \\
\hline \multirow[t]{2}{*}{$\mathrm{Age}^{2}$} & 1.00 & 1.00 & 1.00 & 1.00 & 1.00 \\
\hline & $(0.383)$ & $(0.759)$ & $(0.408)$ & $(0.813)$ & $(0.730)$ \\
\hline \multirow[t]{2}{*}{ Some College } & 0.96 & 1.11 & 0.98 & 1.14 & 1.14 \\
\hline & $(0.847)$ & $(0.676)$ & $(0.923)$ & $(0.597)$ & $(0.591)$ \\
\hline \multirow{2}{*}{ BA or more } & 1.04 & 1.32 & 1.08 & 1.34 & 1.32 \\
\hline & $(0.910)$ & $(0.503)$ & $(0.837)$ & $(0.477)$ & $(0.510)$ \\
\hline \multirow[t]{2}{*}{ Cognitive Skill } & & $0.21^{* * *}$ & & $0.21^{* *}$ & $0.21^{* *}$ \\
\hline & & $(0.010)$ & & $(0.013)$ & $(0.014)$ \\
\hline \multirow[t]{2}{*}{ Extraversion } & & 1.84 & & 1.80 & 2.17 \\
\hline & & $(0.560)$ & & $(0.575)$ & $(0.464)$ \\
\hline \multirow[t]{2}{*}{ Neuroticism } & & $6.45^{* *}$ & & $6.04^{* *}$ & $4.17^{*}$ \\
\hline & & $(0.012)$ & & $(0.016)$ & $(0.072)$ \\
\hline \multirow[t]{2}{*}{ Agreeableness } & & 1.63 & & 1.59 & 1.25 \\
\hline & & $(0.536)$ & & $(0.555)$ & $(0.781)$ \\
\hline \multirow[t]{2}{*}{ Conscientiousness } & & 0.75 & & 0.75 & \\
\hline & & $(0.711)$ & & $(0.709)$ & \\
\hline \multirow[t]{2}{*}{ Inhibitive Side of Consc. } & & & & & 3.54 \\
\hline & & & & & $(0.155)$ \\
\hline \multirow[t]{2}{*}{ Proactive Side of Consc. } & & & & & $0.24^{*}$ \\
\hline & & & & & $(0.066)$ \\
\hline \multirow[t]{2}{*}{ Delay Acceptance } & & & 0.80 & 0.91 & 0.89 \\
\hline & & & $(0.478)$ & $(0.811)$ & $(0.752)$ \\
\hline \multirow[t]{2}{*}{ Risk Acceptance } & & & 0.83 & 0.69 & 0.71 \\
\hline & & & $(0.657)$ & $(0.427)$ & $(0.458)$ \\
\hline $\mathrm{N}$ & 1065 & 859 & 1065 & 859 & 859 \\
\hline
\end{tabular}


Table 14: Determinants of job exits from the company. Job exits include all on-the-job failures, for any choice-based by firm or trainee, which applies only to those completing training.

\begin{tabular}{|c|c|c|c|c|c|}
\hline & (1) & $(2)$ & $(3)$ & (4) & $(5)$ \\
\hline & $\mathrm{b} / \mathrm{p}$ & $\mathrm{b} / \mathrm{p}$ & $\mathrm{b} / \mathrm{p}$ & $\mathrm{b} / \mathrm{p}$ & $\mathrm{b} / \mathrm{p}$ \\
\hline \multirow{2}{*}{ Female } & 0.98 & 1.07 & 0.98 & 1.07 & 1.07 \\
\hline & $(0.865)$ & $(0.683)$ & $(0.865)$ & $(0.670)$ & $(0.672)$ \\
\hline \multirow[t]{2}{*}{ African-American } & $1.48 * * *$ & $1.33^{*}$ & $1.47^{* * *}$ & $1.34^{*}$ & $1.31^{*}$ \\
\hline & $(0.002)$ & $(0.063)$ & $(0.003)$ & $(0.057)$ & $(0.090)$ \\
\hline \multirow[t]{2}{*}{ Native American } & 0.64 & 0.63 & 0.64 & 0.63 & 0.65 \\
\hline & $(0.123)$ & $(0.165)$ & $(0.123)$ & $(0.164)$ & $(0.196)$ \\
\hline \multirow[t]{2}{*}{ Asian } & 1.55 & 0.47 & 1.56 & 0.46 & 0.45 \\
\hline & $(0.398)$ & $(0.470)$ & $(0.393)$ & $(0.455)$ & $(0.449)$ \\
\hline \multirow[t]{2}{*}{ Latino } & $1.59^{*}$ & $1.76^{*}$ & $1.59^{*}$ & $1.76^{*}$ & $1.77^{*}$ \\
\hline & $(0.081)$ & $(0.086)$ & $(0.083)$ & $(0.088)$ & $(0.085)$ \\
\hline \multirow[t]{2}{*}{ Separated } & $1.91 * * *$ & $2.23^{* * *}$ & $1.90^{* * *}$ & $2.24^{* * *}$ & $2.34^{* * *}$ \\
\hline & $(0.001)$ & $(0.001)$ & $(0.001)$ & $(0.001)$ & $(0.000)$ \\
\hline \multirow[t]{2}{*}{ Divorced } & 0.86 & 0.83 & 0.86 & 0.83 & 0.82 \\
\hline & $(0.263)$ & $(0.199)$ & $(0.264)$ & $(0.199)$ & $(0.190)$ \\
\hline \multirow[t]{2}{*}{ Never Married } & 0.97 & 1.03 & 0.97 & 1.03 & 1.03 \\
\hline & $(0.766)$ & $(0.830)$ & $(0.775)$ & $(0.843)$ & $(0.829)$ \\
\hline \multirow[t]{2}{*}{ Age } & 0.97 & 0.95 & 0.97 & 0.95 & 0.95 \\
\hline & $(0.357)$ & $(0.143)$ & $(0.351)$ & $(0.142)$ & $(0.134)$ \\
\hline \multirow[t]{2}{*}{$\operatorname{Age}^{2}$} & 1.00 & 1.00 & 1.00 & 1.00 & 1.00 \\
\hline & $(0.411)$ & $(0.116)$ & $(0.401)$ & $(0.119)$ & $(0.112)$ \\
\hline \multirow[t]{2}{*}{ Some College } & 0.89 & 1.05 & 0.89 & 1.04 & 1.04 \\
\hline & $(0.197)$ & $(0.676)$ & $(0.215)$ & $(0.696)$ & $(0.701)$ \\
\hline \multirow[t]{2}{*}{ BA or more } & $0.74^{*}$ & 0.90 & 0.74 & 0.90 & 0.90 \\
\hline & $(0.088)$ & $(0.618)$ & $(0.101)$ & $(0.591)$ & $(0.589)$ \\
\hline \multirow[t]{2}{*}{ Cognitive Skill } & & $0.41^{* * *}$ & & $0.40^{* * *}$ & $0.40^{* * *}$ \\
\hline & & $(0.003)$ & & $(0.003)$ & $(0.003)$ \\
\hline \multirow[t]{2}{*}{ Extraversion } & & 0.81 & & 0.81 & 0.85 \\
\hline & & $(0.648)$ & & $(0.660)$ & $(0.724)$ \\
\hline \multirow[t]{2}{*}{ Neuroticism } & & 1.00 & & 0.99 & 0.95 \\
\hline & & $(0.995)$ & & $(0.983)$ & $(0.901)$ \\
\hline \multirow[t]{2}{*}{ Agreeableness } & & 0.65 & & 0.65 & 0.63 \\
\hline & & $(0.219)$ & & $(0.212)$ & $(0.188)$ \\
\hline \multirow[t]{2}{*}{ Conscientiousness } & & 1.66 & & 1.64 & \\
\hline & & $(0.211)$ & & $(0.219)$ & \\
\hline \multirow[t]{2}{*}{ Inhibitive Side of Consc. } & & & & & 1.56 \\
\hline & & & & & $(0.273)$ \\
\hline \multirow[t]{2}{*}{ Proactive Side of Consc. } & & & & & 1.12 \\
\hline & & & & & $(0.766)$ \\
\hline \multirow[t]{2}{*}{ Delay Acceptance } & & & 0.96 & 1.08 & 1.08 \\
\hline & & & $(0.778)$ & $(0.641)$ & $(0.654)$ \\
\hline \multirow[t]{2}{*}{ Risk Acceptance } & & & 1.06 & 0.98 & 0.99 \\
\hline & & & $(0.783)$ & $(0.912)$ & $(0.955)$ \\
\hline $\mathrm{N}$ & 951 & 767 & 951 & 767 & 767 \\
\hline
\end{tabular}


Table 15: Determinants of discharges from the company. Discharges are training exits and job exits that were involuntary.

\begin{tabular}{|c|c|c|c|c|c|}
\hline & (1) & (2) & (3) & (4) & $(5)$ \\
\hline & $\mathrm{b} / \mathrm{p}$ & $\mathrm{b} / \mathrm{p}$ & $\mathrm{b} / \mathrm{p}$ & $\mathrm{b} / \mathrm{p}$ & $\mathrm{b} / \mathrm{p}$ \\
\hline \multirow[t]{2}{*}{ Female } & 0.93 & 0.96 & 0.93 & 0.98 & 0.98 \\
\hline & $(0.780)$ & $(0.905)$ & $(0.785)$ & $(0.945)$ & $(0.945)$ \\
\hline \multirow[t]{2}{*}{ African-American } & $2.98^{* * *}$ & $2.23^{* * *}$ & $3.13^{* * *}$ & $2.42^{* * *}$ & $2.58^{* * *}$ \\
\hline & $(0.000)$ & $(0.000)$ & $(0.000)$ & $(0.000)$ & $(0.000)$ \\
\hline \multirow[t]{2}{*}{ Native American } & 0.89 & 0.99 & 0.88 & 0.99 & 0.93 \\
\hline & $(0.800)$ & $(0.981)$ & $(0.783)$ & $(0.989)$ & $(0.887)$ \\
\hline \multirow{2}{*}{ Asian } & 2.08 & 0.00 & 1.97 & 0.00 & 0.00 \\
\hline & $(0.333)$ & $(1.000)$ & $(0.378)$ & $(1.000)$ & $(1.000)$ \\
\hline \multirow[t]{2}{*}{ Latino } & 1.20 & 1.23 & 1.23 & 1.14 & 1.14 \\
\hline & $(0.753)$ & $(0.781)$ & $(0.731)$ & $(0.855)$ & $(0.857)$ \\
\hline \multirow[t]{2}{*}{ Separated } & $3.92^{* * *}$ & $4.42^{* * *}$ & $3.91^{* * *}$ & $4.42^{* * *}$ & $4.28^{* * *}$ \\
\hline & $(0.000)$ & $(0.000)$ & $(0.000)$ & $(0.000)$ & $(0.000)$ \\
\hline \multirow[t]{2}{*}{ Divorced } & 1.29 & 1.29 & 1.29 & 1.33 & 1.31 \\
\hline & $(0.276)$ & $(0.341)$ & $(0.275)$ & $(0.294)$ & $(0.320)$ \\
\hline \multirow{2}{*}{ Never Married } & $1.81^{* * *}$ & $2.11^{* * *}$ & $1.78^{* * *}$ & $2.04^{* * *}$ & $1.98^{* * *}$ \\
\hline & $(0.005)$ & $(0.003)$ & $(0.007)$ & $(0.004)$ & $(0.007)$ \\
\hline \multirow[t]{2}{*}{ Age } & 1.03 & 1.01 & 1.03 & 1.01 & 1.00 \\
\hline & $(0.505)$ & $(0.791)$ & $(0.519)$ & $(0.895)$ & $(0.944)$ \\
\hline \multirow{2}{*}{$\mathrm{Age}^{2}$} & 1.00 & 1.00 & 1.00 & 1.00 & 1.00 \\
\hline & $(0.918)$ & $(0.788)$ & $(0.906)$ & $(0.738)$ & $(0.698)$ \\
\hline \multirow[t]{2}{*}{ Some College } & 0.89 & 1.13 & 0.87 & 1.12 & 1.12 \\
\hline & $(0.503)$ & $(0.552)$ & $(0.418)$ & $(0.581)$ & $(0.592)$ \\
\hline \multirow{2}{*}{ BA or more } & 0.74 & 0.80 & 0.70 & 0.74 & 0.75 \\
\hline & $(0.351)$ & $(0.579)$ & $(0.269)$ & $(0.446)$ & $(0.472)$ \\
\hline \multirow[t]{2}{*}{ Cognitive Skill } & & $0.17^{* * *}$ & & $0.13^{* * *}$ & $0.13^{* * *}$ \\
\hline & & $(0.001)$ & & $(0.000)$ & $(0.000)$ \\
\hline \multirow[t]{2}{*}{ Extraversion } & & 2.32 & & 2.47 & 2.39 \\
\hline & & $(0.351)$ & & $(0.312)$ & $(0.326)$ \\
\hline \multirow{2}{*}{ Neuroticism } & & 1.31 & & 1.12 & 1.21 \\
\hline & & $(0.696)$ & & $(0.871)$ & $(0.788)$ \\
\hline \multirow[t]{2}{*}{ Agreeableness } & & 0.61 & & 0.55 & 0.65 \\
\hline & & $(0.449)$ & & $(0.363)$ & $(0.516)$ \\
\hline \multirow{2}{*}{ Conscientiousness } & & 1.57 & & 1.38 & \\
\hline & & $(0.530)$ & & $(0.655)$ & \\
\hline \multirow[t]{2}{*}{ Inhibitive Side of Consc. } & & & & & 0.53 \\
\hline & & & & & $(0.376)$ \\
\hline \multirow[t]{2}{*}{ Proactive Side of Consc. } & & & & & 1.77 \\
\hline & & & & & $(0.415)$ \\
\hline \multirow[t]{2}{*}{ Delay Acceptance } & & & 1.44 & $2.07^{* *}$ & $2.10^{* *}$ \\
\hline & & & $(0.186)$ & $(0.025)$ & $(0.022)$ \\
\hline \multirow{2}{*}{ Risk Acceptance } & & & 0.75 & 0.59 & 0.58 \\
\hline & & & $(0.417)$ & $(0.175)$ & $(0.155)$ \\
\hline $\mathrm{N}$ & 1065 & 859 & 1065 & 859 & 859 \\
\hline
\end{tabular}


Table 16: Determinants of voluntary quits from the company. Voluntary quits are training exits and job exits that were voluntary.

\begin{tabular}{|c|c|c|c|c|c|}
\hline & (1) & $(2)$ & $(3)$ & (4) & $(5)$ \\
\hline & $\mathrm{b} / \mathrm{p}$ & $\mathrm{b} / \mathrm{p}$ & $\mathrm{b} / \mathrm{p}$ & $\mathrm{b} / \mathrm{p}$ & $\mathrm{b} / \mathrm{p}$ \\
\hline \multirow[t]{2}{*}{ Female } & 1.08 & 1.16 & 1.08 & 1.15 & 1.16 \\
\hline & $(0.612)$ & $(0.364)$ & $(0.615)$ & $(0.391)$ & $(0.370)$ \\
\hline \multirow[t]{2}{*}{ African-American } & $1.45^{* * *}$ & $1.38^{* *}$ & $1.41^{* *}$ & $1.35^{*}$ & 1.27 \\
\hline & $(0.005)$ & $(0.044)$ & $(0.012)$ & $(0.059)$ & $(0.149)$ \\
\hline \multirow[t]{2}{*}{ Native American } & 0.61 & 0.58 & 0.61 & 0.58 & 0.63 \\
\hline & $(0.110)$ & $(0.133)$ & $(0.115)$ & $(0.133)$ & $(0.210)$ \\
\hline \multirow[t]{2}{*}{ Asian } & 1.61 & 1.94 & 1.64 & 1.97 & 1.92 \\
\hline & $(0.356)$ & $(0.288)$ & $(0.335)$ & $(0.271)$ & $(0.286)$ \\
\hline \multirow[t]{2}{*}{ Latino } & $1.65^{*}$ & $1.93^{* *}$ & $1.62^{*}$ & $1.93^{* *}$ & $1.94^{* *}$ \\
\hline & $(0.068)$ & $(0.047)$ & $(0.079)$ & $(0.046)$ & $(0.044)$ \\
\hline \multirow[t]{2}{*}{ Separated } & 1.22 & 1.24 & 1.19 & 1.23 & 1.33 \\
\hline & $(0.414)$ & $(0.477)$ & $(0.474)$ & $(0.494)$ & $(0.347)$ \\
\hline \multirow[t]{2}{*}{ Divorced } & 0.81 & $0.75^{*}$ & 0.81 & $0.75^{*}$ & $0.76^{*}$ \\
\hline & $(0.118)$ & $(0.063)$ & $(0.126)$ & $(0.064)$ & $(0.068)$ \\
\hline \multirow[t]{2}{*}{ Never Married } & 0.89 & 0.91 & 0.90 & 0.92 & 0.92 \\
\hline & $(0.346)$ & $(0.495)$ & $(0.379)$ & $(0.525)$ & $(0.568)$ \\
\hline \multirow[t]{2}{*}{ Age } & 0.97 & 0.95 & 0.97 & 0.95 & 0.95 \\
\hline & $(0.387)$ & $(0.165)$ & $(0.372)$ & $(0.162)$ & $(0.143)$ \\
\hline \multirow[t]{2}{*}{$\mathrm{Age}^{2}$} & 1.00 & 1.00 & 1.00 & 1.00 & $1.00^{*}$ \\
\hline & $(0.401)$ & $(0.119)$ & $(0.368)$ & $(0.111)$ & $(0.096)$ \\
\hline \multirow[t]{2}{*}{ Some College } & 0.90 & 1.03 & 0.92 & 1.04 & 1.03 \\
\hline & $(0.263)$ & $(0.802)$ & $(0.354)$ & $(0.764)$ & $(0.819)$ \\
\hline \multirow[t]{2}{*}{ BA or more } & 0.80 & 1.02 & 0.83 & 1.03 & 1.02 \\
\hline & $(0.216)$ & $(0.941)$ & $(0.321)$ & $(0.870)$ & $(0.920)$ \\
\hline \multirow[t]{2}{*}{ Cognitive Skill } & & $0.45^{* *}$ & & $0.48^{* *}$ & $0.48^{* *}$ \\
\hline & & $(0.011)$ & & $(0.021)$ & $(0.022)$ \\
\hline \multirow[t]{2}{*}{ Extraversion } & & 0.69 & & 0.68 & 0.75 \\
\hline & & $(0.441)$ & & $(0.427)$ & $(0.568)$ \\
\hline \multirow[t]{2}{*}{ Neuroticism } & & 1.43 & & 1.46 & 1.24 \\
\hline & & $(0.337)$ & & $(0.309)$ & $(0.585)$ \\
\hline \multirow[t]{2}{*}{ Agreeableness } & & 0.80 & & 0.82 & 0.72 \\
\hline & & $(0.547)$ & & $(0.587)$ & $(0.390)$ \\
\hline \multirow[t]{2}{*}{ Conscientiousness } & & 1.40 & & 1.43 & \\
\hline & & $(0.413)$ & & $(0.388)$ & \\
\hline \multirow[t]{2}{*}{ Inhibitive Side of Consc. } & & & & & $2.55^{* *}$ \\
\hline & & & & & $(0.028)$ \\
\hline \multirow[t]{2}{*}{ Proactive Side of Consc. } & & & & & 0.65 \\
\hline & & & & & $(0.275)$ \\
\hline \multirow[t]{2}{*}{ Delay Acceptance } & & & 0.79 & 0.84 & 0.83 \\
\hline & & & $(0.129)$ & $(0.325)$ & $(0.276)$ \\
\hline \multirow[t]{2}{*}{ Risk Acceptance } & & & 1.14 & 1.05 & 1.09 \\
\hline & & & $(0.531)$ & $(0.816)$ & $(0.721)$ \\
\hline $\mathrm{N}$ & 1065 & 859 & 1065 & 859 & 859 \\
\hline
\end{tabular}


Table 17: Determinants of accident risk with exposure adjustment.

\begin{tabular}{|c|c|c|c|c|c|}
\hline & $\begin{array}{r}\text { M1wb } \\
\mathrm{HR} /(\text { pval })\end{array}$ & $\begin{array}{r}\text { M2wb } \\
\mathrm{HR} /(\text { pval })\end{array}$ & $\begin{array}{r}\text { M3wb } \\
\mathrm{HR} /(\text { pval })\end{array}$ & $\begin{array}{r}\text { M4wb } \\
\mathrm{HR} /(\text { pval })\end{array}$ & $\begin{array}{r}\text { M5wb } \\
\mathrm{HR} /(\text { pval })\end{array}$ \\
\hline \multirow[t]{2}{*}{ Female } & 1.227 & 1.183 & 1.226 & 1.184 & 1.169 \\
\hline & $(0.192)$ & $(0.315)$ & $(0.194)$ & $(0.315)$ & $(0.340)$ \\
\hline \multirow[t]{2}{*}{ African American } & 1.167 & 1.203 & 1.171 & 1.218 & $1.292^{*}$ \\
\hline & $(0.309)$ & $(0.220)$ & $(0.302)$ & $(0.193)$ & $(0.098)$ \\
\hline \multirow{2}{*}{ Native American } & 1.343 & $1.783^{* *}$ & 1.337 & $1.797^{* *}$ & $1.723^{* *}$ \\
\hline & $(0.300)$ & $(0.011)$ & $(0.312)$ & $(0.012)$ & $(0.023)$ \\
\hline \multirow[t]{2}{*}{ Asian } & 1.028 & 1.791 & 1.019 & 1.775 & 1.828 \\
\hline & $(0.969)$ & $(0.391)$ & $(0.979)$ & $(0.400)$ & $(0.405)$ \\
\hline \multirow[t]{2}{*}{ Latino } & 1.398 & 1.544 & 1.402 & 1.549 & 1.548 \\
\hline & $(0.440)$ & $(0.298)$ & $(0.434)$ & $(0.291)$ & $(0.289)$ \\
\hline \multirow[t]{2}{*}{ Separated } & 0.683 & $0.550^{*}$ & 0.684 & $0.553^{*}$ & $0.520 *$ \\
\hline & $(0.313)$ & $(0.097)$ & $(0.313)$ & $(0.100)$ & $(0.073)$ \\
\hline \multirow[t]{2}{*}{ Divorced } & 1.028 & 0.989 & 1.026 & 0.987 & 0.992 \\
\hline & $(0.828)$ & $(0.932)$ & $(0.842)$ & $(0.921)$ & $(0.951)$ \\
\hline \multirow[t]{2}{*}{ Never Married } & $1.548^{* * *}$ & $1.498^{* * *}$ & $1.547^{* * *}$ & $1.494 * * *$ & $1.494^{* * *}$ \\
\hline & $(0.000)$ & $(0.001)$ & $(0.000)$ & $(0.001)$ & $(0.001)$ \\
\hline \multirow[t]{2}{*}{ Age } & 0.985 & 0.982 & 0.985 & 0.983 & 0.982 \\
\hline & $(0.647)$ & $(0.599)$ & $(0.641)$ & $(0.618)$ & $(0.598)$ \\
\hline \multirow[t]{2}{*}{$\mathrm{Age}^{2}$} & 1.000 & 1.000 & 1.000 & 1.000 & 1.000 \\
\hline & $(0.320)$ & $(0.297)$ & $(0.317)$ & $(0.316)$ & $(0.300)$ \\
\hline \multirow[t]{2}{*}{ Some College } & 1.154 & 1.117 & 1.152 & 1.113 & 1.108 \\
\hline & $(0.170)$ & $(0.325)$ & $(0.177)$ & $(0.340)$ & $(0.362)$ \\
\hline \multirow{2}{*}{ BA or more } & 1.212 & 1.200 & 1.207 & 1.184 & 1.183 \\
\hline & $(0.217)$ & $(0.257)$ & $(0.229)$ & $(0.300)$ & $(0.306)$ \\
\hline \multirow[t]{2}{*}{ Cognitive Skill Index } & & 1.017 & & 1.009 & 1.007 \\
\hline & & $(0.815)$ & & $(0.911)$ & $(0.922)$ \\
\hline \multirow[t]{2}{*}{ Extraversion } & & 1.217 & & 1.231 & 1.118 \\
\hline & & $(0.561)$ & & $(0.540)$ & $(0.739)$ \\
\hline \multirow[t]{2}{*}{ Neuroticism } & & 0.740 & & 0.730 & 0.808 \\
\hline & & $(0.353)$ & & $(0.334)$ & $(0.536)$ \\
\hline \multirow[t]{2}{*}{ Conscientiousness } & & $0.474^{* *}$ & & $0.476^{* *}$ & \\
\hline & & $(0.032)$ & & $(0.033)$ & \\
\hline \multirow{2}{*}{ Agreeableness } & & 1.053 & & 1.031 & 1.147 \\
\hline & & $(0.880)$ & & $(0.930)$ & $(0.688)$ \\
\hline \multirow[t]{2}{*}{ Delay Acceptance } & & & 1.030 & 1.094 & 1.110 \\
\hline & & & $(0.841)$ & $(0.562)$ & $(0.500)$ \\
\hline \multirow[t]{2}{*}{ Risk Acceptance } & & & 1.026 & 0.949 & 0.920 \\
\hline & & & $(0.908)$ & $(0.818)$ & $(0.707)$ \\
\hline \multirow[t]{2}{*}{ Consc-Inhibitive } & & & & & $0.394^{* * *}$ \\
\hline & & & & & $(0.008)$ \\
\hline \multirow[t]{2}{*}{ Consc-Proactive } & & & & & 1.021 \\
\hline & & & & & $(0.954)$ \\
\hline Obs Weeks & 42470 & 40437 & 42470 & 40437 & 40437 \\
\hline Subjects & 949 & 900 & 949 & 900 & 900 \\
\hline Chisq & 178 & 182 & 181 & 182 & 188 \\
\hline df & 46 & 51 & 48 & 53 & 54 \\
\hline
\end{tabular}


Table 18: Determinants of log of Body Mass Index. The dependent variable is the log of BMI. The coefficients reported are standardized $(\beta)$ coefficients.

\begin{tabular}{|c|c|c|c|c|c|}
\hline & $\begin{array}{r}(1) \\
\text { beta/p }\end{array}$ & $\begin{array}{r}(2) \\
\text { beta/p }\end{array}$ & $\begin{array}{r}(3) \\
\text { beta/p }\end{array}$ & $\begin{array}{r}(4) \\
\mathrm{beta} / \mathrm{p}\end{array}$ & $\begin{array}{r}(5) \\
\text { beta/p }\end{array}$ \\
\hline \multirow[t]{2}{*}{ Female } & $0.08^{* *}$ & $0.09^{* *}$ & $0.08^{* *}$ & $0.09^{* * *}$ & $0.09^{* *}$ \\
\hline & $(0.027)$ & $(0.011)$ & $(0.026)$ & $(0.010)$ & $(0.011)$ \\
\hline \multirow[t]{2}{*}{ African-American } & -0.03 & -0.01 & -0.02 & 0.00 & -0.01 \\
\hline & $(0.344)$ & $(0.849)$ & $(0.547)$ & $(0.994)$ & $(0.698)$ \\
\hline \multirow[t]{2}{*}{ Native American } & 0.02 & 0.02 & 0.02 & 0.02 & 0.02 \\
\hline & $(0.562)$ & $(0.634)$ & $(0.508)$ & $(0.579)$ & $(0.514)$ \\
\hline \multirow[t]{2}{*}{ Latino } & 0.05 & 0.05 & 0.05 & 0.05 & 0.04 \\
\hline & $(0.144)$ & $(0.147)$ & $(0.156)$ & $(0.160)$ & $(0.207)$ \\
\hline \multirow[t]{2}{*}{ Separated } & -0.04 & -0.03 & -0.04 & -0.03 & -0.03 \\
\hline & $(0.266)$ & $(0.371)$ & $(0.300)$ & $(0.405)$ & $(0.473)$ \\
\hline \multirow[t]{2}{*}{ Divorced } & -0.06 & -0.06 & -0.06 & -0.06 & -0.05 \\
\hline & $(0.125)$ & $(0.107)$ & $(0.125)$ & $(0.112)$ & $(0.164)$ \\
\hline \multirow{2}{*}{ Never Married } & 0.02 & 0.01 & 0.02 & 0.00 & 0.01 \\
\hline & $(0.602)$ & $(0.896)$ & $(0.634)$ & $(0.929)$ & $(0.891)$ \\
\hline \multirow[t]{2}{*}{ Age } & $0.19 * * *$ & $0.21 * * *$ & $0.18^{* *}$ & $0.20 * * *$ & $0.19^{* * *}$ \\
\hline & $(0.008)$ & $(0.005)$ & $(0.010)$ & $(0.007)$ & $(0.008)$ \\
\hline \multirow[t]{2}{*}{$\mathrm{Age}^{2}$} & $-0.24^{* * *}$ & $-0.26^{* * *}$ & $-0.25^{* * *}$ & $-0.27 * * *$ & $-0.26 * * *$ \\
\hline & $(0.000)$ & $(0.000)$ & $(0.000)$ & $(0.000)$ & $(0.000)$ \\
\hline \multirow[t]{2}{*}{ Some College } & 0.03 & 0.02 & 0.02 & 0.01 & 0.00 \\
\hline & $(0.415)$ & $(0.697)$ & $(0.555)$ & $(0.771)$ & $(0.899)$ \\
\hline \multirow[t]{2}{*}{ BA or more } & 0.01 & 0.01 & -0.00 & 0.00 & -0.00 \\
\hline & $(0.783)$ & $(0.739)$ & $(0.938)$ & $(0.917)$ & $(0.969)$ \\
\hline \multirow{2}{*}{ Cognitive Skill } & & 0.01 & & -0.00 & -0.00 \\
\hline & & $(0.767)$ & & $(0.909)$ & $(0.906)$ \\
\hline \multirow[t]{2}{*}{ Extraversion } & & $0.08^{* *}$ & & $0.08^{* *}$ & $0.08^{* *}$ \\
\hline & & $(0.044)$ & & $(0.045)$ & $(0.036)$ \\
\hline \multirow[t]{2}{*}{ Neuroticism } & & 0.00 & & -0.00 & -0.04 \\
\hline & & $(0.918)$ & & $(0.972)$ & $(0.391)$ \\
\hline \multirow[t]{2}{*}{ Agreeableness } & & 0.01 & & 0.00 & -0.01 \\
\hline & & $(0.828)$ & & $(0.941)$ & $(0.729)$ \\
\hline \multirow[t]{2}{*}{ Conscientiousness } & & $-0.15^{* * *}$ & & $-0.16^{* * *}$ & \\
\hline & & $(0.000)$ & & $(0.000)$ & \\
\hline \multirow[t]{2}{*}{ Inhibitive Side of Consc. } & & & & & 0.03 \\
\hline & & & & & $(0.436)$ \\
\hline \multirow[t]{2}{*}{ Proactive Side of Consc. } & & & & & $-0.21^{* * *}$ \\
\hline & & & & & $(0.000)$ \\
\hline \multirow[t]{2}{*}{ Delay Acceptance } & & & $0.07^{* *}$ & $0.07^{*}$ & $0.07 *$ \\
\hline & & & $(0.040)$ & $(0.050)$ & $(0.074)$ \\
\hline \multirow[t]{2}{*}{ Risk Acceptance } & & & -0.04 & -0.04 & -0.03 \\
\hline & & & $(0.292)$ & $(0.286)$ & $(0.342)$ \\
\hline $\mathrm{r} 2$ & 0.035 & 0.057 & 0.040 & 0.063 & 0.074 \\
\hline $\mathrm{N}$ & 840 & 810 & 840 & 810 & 810 \\
\hline
\end{tabular}


Table 19: Determinants of smoking habit. Logit regressions of the variable equal to one if the subject is a smoker. Marginal effects at the mean of the dependent variables.

\begin{tabular}{|c|c|c|c|c|c|}
\hline & (1) & (2) & (3) & (4) & (5) \\
\hline & $\mathrm{b} / \mathrm{p}$ & $b / p$ & $b / p$ & $\mathrm{~b} / \mathrm{p}$ & $\mathrm{b} / \mathrm{p}$ \\
\hline \multirow{2}{*}{ Female } & 0.02 & 0.04 & 0.01 & 0.03 & 0.03 \\
\hline & $(0.813)$ & $(0.535)$ & $(0.846)$ & $(0.683)$ & $(0.687)$ \\
\hline \multirow[t]{2}{*}{ African-American } & -0.06 & -0.05 & $-0.11^{*}$ & -0.08 & -0.05 \\
\hline & $(0.326)$ & $(0.502)$ & $(0.071)$ & $(0.277)$ & $(0.457)$ \\
\hline \multirow{2}{*}{ Native American } & 0.05 & 0.02 & 0.03 & -0.01 & -0.04 \\
\hline & $(0.699)$ & $(0.911)$ & $(0.827)$ & $(0.925)$ & $(0.800)$ \\
\hline \multirow[t]{2}{*}{ Latino } & -0.13 & -0.06 & -0.13 & -0.06 & -0.06 \\
\hline & $(0.287)$ & $(0.693)$ & $(0.259)$ & $(0.654)$ & $(0.705)$ \\
\hline \multirow[t]{2}{*}{ Separated } & $0.27^{* * *}$ & $0.21 *$ & $0.28^{* * *}$ & $0.23^{* *}$ & $0.21 *$ \\
\hline & $(0.007)$ & $(0.071)$ & $(0.005)$ & $(0.047)$ & $(0.087)$ \\
\hline \multirow[t]{2}{*}{ Divorced } & $0.16^{* * *}$ & $0.13^{* *}$ & $0.17^{* * *}$ & $0.14^{* *}$ & $0.14^{* *}$ \\
\hline & $(0.009)$ & $(0.050)$ & $(0.004)$ & $(0.036)$ & $(0.041)$ \\
\hline \multirow[t]{2}{*}{ Never Married } & 0.07 & 0.04 & $0.09 *$ & 0.05 & 0.05 \\
\hline & $(0.134)$ & $(0.488)$ & $(0.082)$ & $(0.369)$ & $(0.372)$ \\
\hline \multirow{2}{*}{ Age } & 0.00 & 0.01 & 0.00 & $0.01 *$ & $0.01 *$ \\
\hline & $(0.320)$ & $(0.130)$ & $(0.297)$ & (0.099) & $(0.082)$ \\
\hline \multirow[t]{2}{*}{$\mathrm{Age}^{2}$} & $-0.00^{* *}$ & $-0.00^{* *}$ & $-0.00^{*}$ & $-0.00^{* *}$ & $-0.00 * *$ \\
\hline & $(0.032)$ & $(0.015)$ & $(0.054)$ & $(0.020)$ & $(0.014)$ \\
\hline \multirow[t]{2}{*}{ Some College } & $-0.12^{* * *}$ & $-0.12^{* *}$ & $-0.11^{* *}$ & $-0.11^{* *}$ & $-0.11^{* *}$ \\
\hline & $(0.003)$ & $(0.016)$ & $(0.011)$ & $(0.026)$ & $(0.030)$ \\
\hline \multirow[t]{2}{*}{ BA or more } & $-0.26^{* * *}$ & $-0.23^{* * *}$ & $-0.23^{* * *}$ & $-0.19^{* *}$ & $-0.18^{* *}$ \\
\hline & $(0.000)$ & $(0.001)$ & $(0.001)$ & $(0.013)$ & $(0.022)$ \\
\hline \multirow{2}{*}{ Cognitive Skill } & & -0.14 & & -0.05 & -0.05 \\
\hline & & $(0.293)$ & & $(0.744)$ & $(0.733)$ \\
\hline \multirow{2}{*}{ Extraversion } & & -0.12 & & -0.20 & -0.27 \\
\hline & & $(0.567)$ & & $(0.360)$ & $(0.226)$ \\
\hline \multirow[t]{2}{*}{ Neuroticism } & & -0.09 & & -0.04 & -0.02 \\
\hline & & $(0.558)$ & & $(0.803)$ & $(0.921)$ \\
\hline \multirow[t]{2}{*}{ Agreeableness } & & $-0.31^{* *}$ & & $-0.29^{*}$ & -0.23 \\
\hline & & $(0.039)$ & & $(0.063)$ & $(0.139)$ \\
\hline \multirow[t]{2}{*}{ Conscientiousness } & & -0.26 & & -0.20 & \\
\hline & & $(0.144)$ & & $(0.271)$ & \\
\hline Inhibitive Side of Consc. & & & & & $\begin{array}{c}-0.41^{* *} \\
(0.028)\end{array}$ \\
\hline Proactive Side of Consc. & & & & & $\begin{array}{r}0.04 \\
(0.807)\end{array}$ \\
\hline \multirow[t]{2}{*}{ Delay Acceptance } & & & $-0.29 * * *$ & $-0.31 * * *$ & $-0.31^{* * *}$ \\
\hline & & & $(0.000)$ & $(0.000)$ & $(0.000)$ \\
\hline Risk Acceptance & & & $0.18^{*}$ & $0.25^{* *}$ & $0.24^{* *}$ \\
\hline & & & & & \\
\hline $\mathrm{N}$ & 654 & 549 & 654 & 549 & 549 \\
\hline
\end{tabular}

